DOI: 10.2478/linpo-2013-0008

\title{
WORD ORDER AND CONSTITUENCY OF SERIAL VERB CONSTRUCTIONS ${ }^{1}$
}

\author{
YONGZHONG YANG
}

\begin{abstract}
Yongzhong Yang. Word Order and Constituency of Serial Verb Constructions. Lingua Posnaniensis, vol. LV (1)/2013. The Poznań Society for the Advancement of the Arts and Sciences. PL ISSN 0079-4740, ISBN 978-83-7654-273-7, pp. 111-151.
\end{abstract}

The goal of this paper is to provide a unified account of word order and constituency of serial verb constructions (SVCs) in the framework of generative grammar. It is argued that both SVO-type and SOV-type SVCs follow the Temporal Iconicity, which is associated with the asymmetric nature of syntactic structure, i.e. V1 or VP1 c-commands V2 or VP2 asymmetrically. Based on this argument, an analysis for the derivation of SVCs - Inter-VP Asymmetrical C-command Analysis - is proposed to account for the derivation of SVCs in various languages. It is argued that in the SVC there exists a null predicate and a null argument, the occurrence or non-occurrence of which gives rise to different types of SVCs. Furthermore, left peripheral deletion (LPD) triggers the movement of VP1's Spec to [Spec IP] and the occurrence of VP2's Spec as pro, as a result of which VP1 asymmetrically c-commands VP2. Object gapping triggers the ATB movement of VP2 to generate various types of SVCs. The differences between coordinative constructions, pivotal constructions and SVCs lie in their internal structure but not in the verb position.

Yongzhong Yang, Faculty of Applied Foreign Language Studies, Yunnan University of Finance and Economics, Kunming, China, wmyoung@sina.com

\section{INTRODUCTION}

Serial verb constructions (SVCs) are phenomena that occur cross-linguistically in a number of the world's languages; they occur most frequently in African, Asian, and Creole languages of the Atlantic and Pacific. They have been extensively discussed in the literature on African and Chinese linguistics (StahlKe 1970; SChachter 1974; JANSEN et al. 1978; Li \& Thompson 1981; Sebba 1987; Baker 1989; Campbell 1989; Dai 1990; Chang 1990; Schiller 1991; Lefebvre 1991; Collins 1997; Liu 1997; Carstens 2002; Kari 2003; Aikhenvald 2005; Li 1991, 2007; YANG 2009; ABOH 2009; MÜLleR \& LiPenKova 2009; TAO 2009; among others). However, there are still some outstanding problems, regarding the types of serial verbs, range of semantic notions that can be expressed by these verbs, and the positions of verbs and objects as complements. Specifically, the problems lie in the following respects: the internal structure of SVCs, the arrangement of the verbs and their objects,

${ }^{1}$ I would like to thank an anonymous reviewer for helpful comments. All errors are mine. 
the reason why V1 always precedes V2 in terms of linear structure and syntactic hierarchy with no regard to linguistic typology, constraints that the constituents are subject to, the generation mechanism of SVCs, the underlying structure which licenses two transitive verbs to occur in a single clause, and the reason for the missing arguments.

The goal of this paper is to provide a unified account of word order and constituency of SVCs in the framework of generative grammar. It is argued that all types of SVCs obey the Temporal Iconicity, which is associated with the asymmetric nature of syntactic structure. Based on this argument, an analysis for the derivation of SVCs - Inter-VP Asymmetrical C-command Analysis - is proposed to account for the derivation of SVCs in various languages. SVCs arise from the deletion of the conjunction between two clauses and left peripheral deletion (LPD). LPD triggers the movement of VP1's specifier to [Spec IP] and the occurrence of VP2's specifier as pro. Object gapping triggers the ATB movement of VP2 to generate various types of SVCs. By analyzing numerous linguistic facts of this construction in various languages and exploring the leading divergence in the definition of its intension and extension, the author illustrates the theoretical justification for the existence of this construction in the framework of generative grammar. Furthermore, a new definition of SVCs is given, based on the linguistic facts of various languages. According to the new definition, SVCs exist not only in phrases, but also in words. After that, the criteria for VP1 and VP2, their morphological differences with other similar structures, the syntactic and semantic relation of $\mathrm{V}+\mathrm{V}$ construction and its syntactic functions are also elaborated. According to the relation between VP1 and VP2, the semantic structure of this construction is classified into two types: one is syntactic-semantic relation; the other is logical-semantic relation. Meanwhile the differences between $\mathrm{V}+\mathrm{V}$ construction and other similar structures are explained.

The organization of the paper is as follows. Section 2 summarizes BAKER (1989) and LI (2007). Section 3 presents some problems for their proposals. Section 4 makes a proposal for the treatment of word order and constituency of SVCs in various languages. Section 5 discusses LPD, object gapping, and generation of SVCs. Section 6 summarizes the results.

\section{RELEVANT RESEARCH}

BAKER (1989) defines SVCs as "constructions in which a sequence of verbs occurs in what seems to be a single clause." Usually, there is only one tense/aspect specification for the whole chain of verbs; the verbs have a single structural subject and share logical arguments. He claims that SVCs behave differently in different languages with respect to coordinations, embedded clauses, or adjectival predicates (small clauses), and that the key difference between serializing languages and nonserializing languages can be expressed as a parameter. If V1 of an SVC takes an object, V2 must theta-mark this object as well. Current versions of Theta-Criterion can allow an argument to receive more than one thetarole as long as all its theta-roles are assigned to the same structural position (BAKER 1989). Therefore, one crucial element in this structure is that V2 must be able to assign a theta-role to an NP, and that the NP is in the object position of V1 and V2. In addition, it also explains that no object can occur behind V2 because it cannot assign two internal theta-roles. This double-headed structure creates the possibility and obligation of two verbs to theta-mark the same internal argument, in accordance with the Projection Principle (WANG 2007). 
Based on this argument, BAKER (1989) argues that universal grammar can account for the Temporal Iconicity ${ }^{2}$ in SVCs as long as it has the following mechanism.

A phrase has one or more than one head.

The order within the phrase is $\mathrm{VO}$ or $\mathrm{OV}$; no constituent with different syntactic quality can intervene between the head and the object; constituents with different syntactic quality can intervene between the subject and the predicate.

In this set of definitions, (1a) determines whether SVCs exist in a language. In other words, a multi-head phrase is the basis for SVCs. (1b) and (1c) are applicable to any language, as illustrated in (2).

$$
\text { awá ótsi ikù utsì }
$$

Yatye (STAHLKE 1970)

take stick close door

'take the stick and close the door'

As (2) shows, VP has two heads V1 and V2. NP1 is the accusative object of V1 and the instrument object of V2, which satisfies (1c). In this phrase, there are two pairs of structural VO combinations, i.e. V1NP1 and V2NP2. The word order of Yatye determines the verb's preceding the object in each combination. NP1, semantically, is also the instrument object of V2. Structurally, the relationship between NP1 and V2 is subject-predicate, for V2 and NP2 have constituted a VO combination, and NP1 lies outside the combination V'. Since there exists a structural subject-predicate relationship, NP1 has to lie to the left of V', which satisfies the SV word order of Yatye. In a word, as the internal structure of VP in Yatye, (2) satisfies the requirements as stipulated in (1).

As opposed to Yatye, the word order of Ijo is SOV. On the premise of object-sharing, the structure of SVCs in Ijo may be as follows:

$$
\text { zu-ye ákì buru teri-mí }
$$

Ijo (WILLIAMSON 1965)

basket take potato cover

'take the potato and cover the basket'

$$
\text { [ }{ }_{V P} \mathrm{NP} 1 \text { zu-ye V1 ákì [ }{ }_{\mathrm{V}} \mathrm{NP} 2 \text { buru V2 teri-mí]] }
$$

*buru teri-mí zu-ye ákì potato cover basket take

As the instrument object of V2, NP1 is structurally V2's subject. (3) satisfies (1), because the semantic relationship between NP1 and V' is subject-predicate, and constituents with different syntactic quality, such as V1, can intervene between the subject and the predicate. Similarly, in (4b), NP1 lies behind V2, which violates the subject-predicate requirement of Ijo. Thus (4) is ruled out as ungrammatical.

2 There is a clear correlation between verb order and iconicity: verbs (VPs) that denote a prior event precede those that denote a posterior event. The linear ordering of V1 and V2 mirrors the sequential ordering of the events they describe. V1 precedes V2 because the former's occurrence is prior to that of the latter.

${ }^{3}$ Collins (1997) also argues that in a serial verb construction, V1 and V2 must share an internal argument. 
Different from BAKER (1989), Li (2007) proposes the concept of Object Co-reference Chain, in which one object functions as the antecedent while the other is a null element, marked by e. In this case, the structure of an SVC should be as follows:

$$
\begin{aligned}
& {\left[{ } _ { V P } V 1 N P 1 _ { i } \left[e_{X} \text { e } 2\right.\right. \text { NP2]] }} \\
& \text { [VP V1 awá NP1 ótsi }{ }_{i}\left[_{X} e_{i}\right. \text { V2 ikù NP2 utsì ]] } \\
& \text { take stick close door } \\
& \text { 'take the stick and close the door' } \\
& \text { * }\left[_{V P}\left[_{X} e_{i} \text { V2 ikù NP2 utsì ]V1 awá NP1 ótsi }{ }_{i}\right]\right. \\
& \text { close door take stick } \\
& \text { * [ } \left.{ }_{\mathrm{VP}} \mathrm{e}_{\mathrm{i}} \mathrm{V} 2 \text { ikù NP2 utsì [ }{ }_{\mathrm{VP}} \mathrm{V} 1 \text { awá NP1 ótsi }{ }_{\mathrm{i}}\right] \text { ] } \\
& \text { close door take stick }
\end{aligned}
$$

The antecedent in the object co-reference chain must asymmetrically c-command the null element. Thus, V1's accusative object, NP1, co-refers with V2's instrument object, e. Furthermore, e must be c-commanded by NP1, but not vice versa. He stresses that object co-reference means that the objects of two verbs form an object chain, in which $\mathrm{O} 1$ asymmetrically c-commands $\mathrm{O} 2$ and $\mathrm{O} 2$ is null. Therefore, Amba and en "her" in (6) does not belong to the class of SVCs with object co-reference, and there is no c-command between them. Furthermore, whether they co-refer with each other does not force en to be structurally lower than Amba. Li (2007) concludes that without object co-reference or object-sharing, the mechanism described by formal grammar (cf. BAKER 1989) cannot determine the word order between two verbs and their positions in terms of the internal structure.

$$
\begin{aligned}
& \text { Kofi naki Amba kiri en } \\
& \text { Kofi hit Amba kill her } \\
& \text { Kofi struck Amba dead. }
\end{aligned}
$$

\section{PROBLEMS WITH THE PROPOSALS}

As Li (2007) and YANG (2009) point out, BAKER's (1989) theory has much limitation. It is only applicable to object-sharing SVCs. But it cannot account for non-object-sharing SVCs. Even if SVCs are characteristic of object-sharing, it fails to provide a reasonable explanation for some data.

$$
\begin{aligned}
& \text { [VP V1 lu NP màálù [v, V2 kú]] } \\
& \text { beat cow die } \\
& \text { 'beat the cow dead' } \\
& \text { *[VP[V, V2 kú [V1 lu NP màálù }]]] \\
& \text { die beat cow } \\
& {\left[{ } _ { V P } V 1 \text { sè } N P \text { eran } \left[V_{V}, V 2\right.\right. \text { tà]] }}
\end{aligned}
$$$$
\text { cook meat sell }
$$$$
\text { 'cook meat and sell it' }
$$

$$
\begin{aligned}
& \text { *[VP } \mathrm{V} 2 \text { tà NP eran [V.V1 sè]] } \\
& \text { sell meat cook }
\end{aligned}
$$


(9a)

$$
\begin{array}{cll}
{\left[{ }_{\mathrm{VP}} \mathrm{NP}\right. \text { ingo V1 }} & \text { dérì [ }{ }_{\mathrm{V}}, \mathrm{V} 2 & \text { pite-mí] }] \\
\text { trap } & \text { weave } & \text { set }
\end{array}
$$

Ijo (WiLliamson 1965)

'weave the trap and set it'

$$
\begin{aligned}
& \text { * [ }{ }_{\mathrm{VP}} \mathrm{NP} \text { ingo V2 pite-mí [V. V1 dèrì]] } \\
& \text { trap set weave }
\end{aligned}
$$

In (7), màálù is not only the accusative object of V1 but also the semantic object of V2, for the latter is an unaccusative verb. In (7a), V1NP is VO, and NPV' is subject-predicate, which satisfies the requirement of word order ofYoruba. In (7b), V1NP is VO, and V2NP is predicatesubject, which does not satisfy the requirement of word order of Yoruba. As a result, it is ungrammatical. In (8), the two constructions are identical, in which both V1 and V2 are transitive verbs, which satisfies the requirement of (1). Nevertheless, (8a) is grammatical while (8b) is ungrammatical. (9) is similar to (8). Similarly, BAKER (1989) fails to account for (10) and (11).

$$
\begin{aligned}
& \text { John Mary-ra pruk-an Bill plap-an } \\
& \text { John Mary-ACC beat Bill run-PST }{ }^{3} \\
& \text { 'John beat Mary and Bill ran.' } \\
& \text { Kofi naki Amba kiri en } \\
& \text { Kofi hit Amba kill her } \\
& \text { 'Kofi struck Amba dead.' }
\end{aligned}
$$$$
\text { Miskito (Li 1991) }
$$

In addition, BAKER (1989) fails to account for SVC compounds. If the SVC compounds are formed by means of word-building rules, the structure of V-V compounds in Chinese, Korean, Yoruba, and Ijo should be as follows (cf. LI 1990):

$$
\text { zhui lei }
$$

chase tired 'chasing makes sb. tired/sb. feels tired because of chasing'

Sranan (BAKER 1989)

$$
\text { [VP V1 zhui V2 lei] }
$$

da si

Chinese

beat die

kill

$$
\text { [VP V1 da V2 si] }
$$

$$
\text { twutulki-e pwusi-ess-ta }
$$

Korean

beat break

break

$$
\text { [VP V1 twutulki-e V2 pwusi-ess-ta] }
$$

$$
\text { lu kú }
$$

beat die

Chinese

kill

${ }^{4}$ The abbreviations used in this paper are as follows: ACC = accusative, AUX = auxiliary word, $\mathrm{CLASS}=$ classifier, $\mathrm{CONJ}=$ conjunction, $\mathrm{DEC}=$ declarative, $\mathrm{FUT}=$ future, $\mathrm{GEN}=$ genitive, $\mathrm{NOM}=$ nominative, $\mathrm{PL}=$ plural, $\mathrm{PST}=$ past, $\mathrm{REF}=$ reference, $\mathrm{SG}=$ singular, $1=$ first person, $3=$ third person. 
weave set

weave and set

[ ${ }_{\mathrm{VP}} \mathrm{V} 1$ dérì $\mathrm{V} 2$ pite-mí]

The word order between V1 and V2 is not constrained by (1), but they conform to the Temporal Iconicity. The word order within VC compounds in Chinese is head + nonhead, and the word order within VC compounds in Korean, Yoruba and Ijo is nonhead + head. However, both of the types can derive VC compounds headed by V1. In Chinese, the structure of VC compounds is consistent with their syntactic structure. In Korean, Yoruba and Ijo, however, the structure of VC compounds is contrary to their syntactic structure. ${ }^{5}$ Why can't VC compounds identical to their syntactic structure be formed by means of head movement? Similarly, BAKER (1989) fails to account for such Chinese compounds as changku "sing-cry" and yanzou "act-walk" in (17).

$$
\begin{array}{lllll}
\text { nashou } & \text { ge } & \text { changku le } & \text { henduo ren } \\
\text { that-CLASS } & \text { song } & \text { sing-cry PST } & \text { many } & \text { people }
\end{array}
$$
'That song made people cry.'

zhechu xi yanzou le yiban guanzhong Chinese (Li 2007) this-CLASS play act-walk PST a half audience

'This play made half of the audience leave.'

Obviously, whether these compounds are derived in morphology or syntax is beyond BAKER (1989).

Similarly, LI's (2007) approach fails to account for the specific features of the null element and the antecedent as well as their structural relationship. If they are the anaphor and its antecedent, NP2 cannot be a null element. If they are the moved constituent and its trace, the trace must be governed. Furthermore, this approach is applicable to nothing but SVCs in Yatye. Secondly, in the case of object co-reference, how the internal relationship and word order of SVCs are determined remains a problem. Specifically, the problem lies in the following respects: the determinants of the word order between the verbs of SVCs, the formation of SVC compounds (including VC compounds in Chinese, Korean, Yoruba and Ijo), the reason for non-co-reference, linearity or hierarchy between the constituents, the asymmetry between co-reference and c-command in Sranan as well as the relevance between co-reference or non-co-reference and hierarchical positions and linear order. Following Li's (2007) analysis, the structure of Chinese SVCs such as yong / na xiaomi zhuzhou "use / take millet cook gruel, i.e. cook gruel with millet" and yong / na kuaizi chi fan "use / take chopsticks eat rice, i.e. eat rice with chopsticks" should be as follows:

$$
\begin{gathered}
*{ }_{\mathrm{VP}} \mathrm{V} 1 \text { yong / na NP xiaomi } \\
\text { use / take millet } \left.{ }_{\mathrm{VP}} \mathrm{e}_{\mathrm{i}} \mathrm{V}^{\prime} \text { zhuzhou }\right] \\
\text { cook-gruel }
\end{gathered}
$$

5 The aspectual V-V in Korean is formed of a main lexical verb, V1, and an aspectual verb, V2, which together form a single aspectual class such as activity and accomplishment. The external and internal arguments are introduced by the lexical V1 and no argument structure contribution is made from the aspectual V2. The serial $\mathrm{V}-\mathrm{V}$ construction formed of two lexical verbs (transitive or intransitive), comes with its own argument structure. The aspectual V-V where the V2 determines eventuality of the aspectual classes (e.g., activity, accomplishment), thus requiring the internal argument to raise to identify the relevant eventuality (cf. vAN HouT 1998; CHOI 2003). 


$$
\begin{gathered}
{ }_{[\mathrm{VP}} \mathrm{V} 1 \text { yong / na NP kuaizi }{ }_{\mathrm{i}}\left[\mathrm{VP}_{\mathrm{i}} \mathrm{e}_{\mathrm{i}} \mathrm{V}^{\prime}\right. \text { chifan] } \\
\text { use / take chopsticks eat-rice }
\end{gathered}
$$

However, neither xiaomi nor kuaizi can be the agents or experiencers of zhuzhou or chifan. Thus, LI's (2007) approach fails to provide a satisfying explanation of the Temporal Iconicity in SVCs.

Furthermore, both BAKER (1989) and Li (2007) fail to account for the word order of V1 and V2. Suppose V1 and V2 represent the event which occurs first and the event which occurs subsequently, V1 always precedes V2 in terms of linear order. Secondly, if V1 and V2 share the same internal argument, only $\mathrm{O} 2$ can be omitted. Furthermore, the problems with BAKER (1989) and Li (2007) lie in the following respects: the reason why V2 is not allowed to precede V1, the syntactic-semantic relationship between V1 and V2, the reason why only $\mathrm{O} 2$ can be omitted, the reason why some SOV-type SVCs follow the Temporal Iconicity whereas others do not, the reason why only SOV-type SVCs allow V2 to precede V1, as well as the way of generation and constraints.

\section{A NEW APPROACH TO WORD ORDER AND CONSTITUENCY OF SVCS: INTER-VP ASYMMETRICAL C-COMMAND ANALYSIS}

In order to solve the above problems, we present a new approach to SVCs and give a new explanation of the word order-related facts. According to DiXON (1997: 339-344), the features of SVCs are as follows: 1) an SVC consists of more than one verb, but the SVC is conceived of as describing a single action; 2) there is no mark of linkage or subordination in an SVC; 3) each verb in an SVC may also occur as the sole verb in a clause; 4) an SVC functions like a single predicate; 5) an SVC will generally have its own transitivity value; 6) there must almost always be (at least) one argument shared by all the verbs in an SVC; 7) the verbs in an SVC may make up one word, or may remain separate words; 8) asymmetrical SVCs tend to become grammaticalized, and symmetrical SVCs tend to become lexicalized; 9) although most SVCs in a language involve just two verbs, in most languages there can be three or more verbs involved.

Based on the above features, we argue that an SVC is based on semantic-grammatical category chain. Semantically, it describes two or more than two actions or behavior made by the same subject. Grammatically, it refers to a construction in which two or more successive verbs are joined together with no connecting particle, clitic, etc. It describes a complete event, which may be composed of more than one subevent, which can be encoded and conceptualized as interrelated and connected in accordance with a certain order (MATTHEWs 2000: 339; DAI \& QIU 2008). It is a succession of verbs and their complements (if any) with one subject and one tense value that are not separated by any overt marker of coordination or subordination (CoLLINs 1997). SVCs describe what is conceptualized as a single event. They are monoclausal; their intonational properties are the same as those of a monoverbal clause, and they have just one tense, aspect, and polarity value. SVCs may also share core and other arguments. Each component of an SVC must be able to occur on its own. Each argument of the verb must have a theta-role, which can be played by only one argument (LARSON 1988). A verb can have various numbers of theta-roles. Hence, in the syntactic system there are levels of conceptual system, namely, the first level of VP1 conceptual system which centers 
on V1 $1^{6}$ and the second level of VP2 conceptual system which centers on V2. In the first level of the VP1 conceptual system, V1 has two arguments ${ }^{7}$, i.e. an external argument, which functions as the sentential subject, and an internal argument, which functions as the object of V1. The theme of the external argument is not assigned by the predicate but by its maximal projection. ${ }^{8}$ In the case of the internal argument, an empty predicate occupies a position in the representation. The specifier of the empty predicate is occupied by an external argument, and its complement is the maximal projection of the major predicate, namely, the structural representations with a variety of internal arguments as shown in (19). In the second level of lexicon, which corresponds to the second level of the conceptual system, NP2 is an internal argument, which is higher in the thematic hierarchy, and NP3 is an internal argument which is lower in the thematic hierarchy. In the first level of lexicon, which corresponds to the first level of the conceptual system, NP1 is an external argument, which is higher in the thematic hierarchy, and NP3 is an external argument, which is lower in the thematic hierarchy. This arrangement can satisfy the hierarchical requirement of the conceptual system and the syn-

6 Авон (2009) argues that in V1-XP-V2 and V1-V2-XP series, V1 merges in the functional domain of the lexical verb V2. V2 introduces the internal argument and is embedded under an AspP whose head is endowed with an EPP feature. Surface word order variations in Kwa (and Khoisan) result from the EPP licensing that triggers V2-object inversion, sometimes followed by V2 movement past the shifted object.

7 This statement is supported by evidence. According to YANG (2007a, b, 2011), intransitives can be followed by objects, as illustrated below:

(i) a. Zhangsan pao zhibiao.

Zhangsan run quota

'He runs about the quota.'

b. Zhangsan zou gangsi.

Zhangsan walk wire

'Zhangsan walks on the wire.'

c. Zhangsan shui yaodong

Zhangsan sleep cave-dwelling

'Zhangsan sleeps in the cave dwelling.'

d. Zhangsan fei Shanghai

Zhangsan fly Shanghai

'Zhangsan flies to Shanghai.'

e. Zhangsan guang gongyuan.

Zhangsan stroll park

'Zhangsan strolls in the park.'

As for the English verb die, it can be followed by an object, as illustrated below:

(ii) a. I'm proud to tell you that your son died a hero. (Rundell M. et al. 2003. MacMillan English Dictionary for Advanced Learners. Beijing: Foreign Language Teaching and Research Press, p. 383)

b. She died a rich woman. (Procter P. et al. 1978. Longman Dictionary of Contemporary English. Harlow-London: Longman Group, p. 303)

c. She died a virgin. (The editorial board of The English-Chinese Dictionary. 2004. The English-Chinese Dictionary. Beijing: The Commercial Press International, p. 446)

d. He died a poor man. (WeHmeIER S. et al. 2004. Oxford Advanced Learner's English-Chinese Dictionary. Beijing: The Commercial Press, Oxford University Press, p. 470)

It must be pointed out that the conceptual system and the syntactic system impose different requirements on the lexical-semantic structure.

8 We assume that V1 and V2 are transitive verbs, or rather, they both can assign accusative Case to nouns which follow them. If V2 is an intransitive verb, even if the preceding NP has the feature of an experiencer, it should not be regarded as an external argument (e.g. Yatye, Kwa, Yoruba), because SVCs require that the verbs in the sentence share the subject. 
tactic system, i.e. a head can have only one specifier and one complement (cf. CHENG 1999: 239-240). According to Sportiche (1988), Kuroda (1988), and Larson (1988, 1990), the assignment of thematic roles is locally constrained. The predicate must assign theta-roles to the arguments within its projection. Thus the argument must occur within the maximal projection of the predicate. The theta-role of the external argument is not assigned by the predicate, but by the maximal projection of the predicate. In order to satisfy these constraints, the lexicon of SVCs adopts the form as shown in (19).

$$
\begin{aligned}
& {\left[{ } _ { \mathrm { VP } 1 } \mathrm { NP } 1 \left[_ { \mathrm { V } ^ { \prime } } \mathrm { V } 1 \text { (major predicate) } \left[{ }_{\mathrm{VP} 2} \mathrm{NP} 2\right.\right.\right. \text { (empty argument) }} \\
& {\left[\mathrm{V}^{\mathrm{V}} \mathrm{V} 2\right. \text { (empty predicate) NP3]]]] }}
\end{aligned}
$$

In the light of (19), in the event of an external argument, an empty predicate occurs in the representation and the specifier position of the empty predicate is occupied by an external argument, the complement of which is the maximal projection of the major predicate, i.e. the structural representation with various internal arguments. In the second level of lexicon, which corresponds to the second level of the conceptual system, NP2 is a higher internal argument and NP3 is a lower external argument in the thematic hierarchy. In the first level of lexicon, which corresponds to the first level of conceptual system, NP1 is a higher external argument $^{9}$ and NP3 is a lower external argument in the thematic hierarchy. The representation of the external argument entails an empty argument position and an empty predicate position, for there is some asymmetry between the conceptual system and the syntactic system. The conceptual system cannot correspond to the syntactic structure until it has been conceptualized..$^{10}$ At first, the conceptual system, which is hierarchic, contains two levels. Hence syntactically NP3 is of dual property and there exists an empty predicate position. In this case it can satisfy both the hierarchic requirement of the conceptual system and the requirement that in the syntactic system one head contain only one specifier and one complement. Secondly, the verb is transitive, and it can assign a theta-role to the internal argument within its maximal projection on its own. VP assigns a theta-role to NP3. Since there is a theta-role in the conceptual system, the syntactic system must provide an empty predicate position in order to reach symmetry between the conceptual system and the syntactic system. Besides, since the external argument is not assigned a theta-role by the predicate, it must be excluded from the maximal projection of the predicate. In this case, to set an empty predicate position in the above structure and to assume that VP1 assigns a theta-role to NP3 by means of VP2 can avoid theoretical inconsistency. Based on this, SVCs in various languages can be accounted for in a unified framework ${ }^{11}$, as illustrated in (20).

9 The external argument is often assumed to be introduced by the light verb $v$ (CHOMSKY 1995) or voice (Kratzer 1996) which is above VP level, but below TP. The light verb $v$ is then responsible for assigning the agentive theta-role as well as licensing the transitive verb form, and hence checks the accusative Case (CHOI 2003).

${ }^{10}$ JACKENDOFF (1990) argues that the conceptual structure corresponds to the syntactic structure. Based on this argument, TAI (2002) proposes that semantics which the syntactic structure can express is abstract and simplified after having been conceptualized instead of rich semantics containing the conceptual system.

${ }^{11}$ SVCs in different languages behave differently in terms of surface structure, but they are the same in terms of underlying structure. Hence they can be accounted for in a unified framework.

(i) a. San Kofi teki koti a brede? Sranan what Kofi take cut the bread 'What did Kofi cut the bread with?' 
(20a)

$$
\begin{aligned}
& {\left[{ }_{V P} N P \text { wo }\left[V^{V} V \text { zhuazhu }\left[{ }_{V P} N P \text { shuzhi }{ }_{i}\left[V_{V} V \text { pashangqu } N_{i}\right]\right]\right]\right]} \\
& 1 \mathrm{SG} \text { grasp branch climb-up }
\end{aligned}
$$

$$
\begin{aligned}
& {\left[_ { V P } N P \text { Chelswu-ka } \left[_{V}, V\left[_ { V P } N P \text { chayksang-ul } { } _ { i } \left[_ { V ^ { \prime } } \text { 'V twutulki-e } \left[_ { V P } \left[_{V^{\prime}} V\right.\right.\right.\right.\right.\right.} \\
& \text { table beat }
\end{aligned}
$$

pwusi-ess-ta $\mathrm{NP}_{\mathrm{i}}$ ]]]]]]

break

$$
\begin{aligned}
& \text { [VP NP Ìywi [ }{ }_{V} \text { V awá[ }{ }_{V P} \text { NP ótsi [ } V_{V} \text { V ikù NP utsì ]]]] } \\
& \text { child take stick close door }
\end{aligned}
$$

b. (*)San Kofi teki a nefi koti?

Sranan

what Kofi take the knife cut

'What did Kofi cut with the knife?'

(ii) a. Zhangsan na shenme qie mianbao?

Chinese

Zhangsan take what cut bread

'What did Zhangsan cut the bread with?'

b. Zhangsan na dao qie shenme?

Chinese

Zhangsan take knife cut what

'What did Zhangsan cut with the knife?'

c. *Shenme Zhangsan na qie mianbao?

Chinese

what Zhangsan take cut bread

d. *Shenme Zhangsan na dao qie?

what Zhangsan take knife cut

Chinese

The contrast in (i) suggests that the first verb, teki "take", is the matrix verb and thus allows its complement to be freely extracted. The second verb, koti "cut", may be treated either as a structural complement of the matrix verb (also see LEFEBVRE 1991) or as an adjunct, resulting in the typical island effect and explaining why some speakers find (ib) unacceptable. However, in (ii), both the complement of V1 and the complement of V2 can be extracted, which is slightly different from that in Sranan. The contrast in (ii) suggests that the wh-phrase shenn$m e$ "what" cannot be moved to the position [Spec $\mathrm{CP}$ ] because there is no inflection in Chinese and there is no motivation to trigger wh-movement. The wh-phrase shenme remains in situ because it is a wh-argument. TsaI (1994) argues that though wh-adverbials undergo covert movment, wh-arguments do not. It follows that both the complements of the verbs in SVCs can be extracted unless the extracted constituents remain in situ. In terms of extraction of the complement of V2, wh-movement gives rise to a Subjacency violation while wh-in-situ does not. It further testifies the plausibility of VP2's being c-commanded by VP1.

(iii) a. $\left[_{\mathrm{CP}} \operatorname{Spec} \operatorname{San}\left[{ }_{\mathrm{TP}}\left[{ }_{\mathrm{VP}} \mathrm{NP}\right.\right.\right.$ Kofi $\left[{ }_{\mathrm{V}} \mathrm{V}\right.$ teki $\left[{ }_{\mathrm{VP}} \mathrm{NP} \mathrm{t}_{\mathrm{San}}\left[{ }_{\mathrm{V}} \mathrm{V}\right.\right.$ koti $\mathrm{NP}$ a brede $\left.\left.\left.\left.\left.]\right]\right]\right]\right]\right]$

b. ${ }^{*}\left[_{\mathrm{CP}} \operatorname{Spec} \operatorname{San}\left[{ }_{\mathrm{TP}}\left[{ }_{\mathrm{VP}} \mathrm{NP}\right.\right.\right.$ Kofi $\left[{ }_{\mathrm{V}} \mathrm{V}\right.$ teki[$\left[_{\mathrm{VP}} \mathrm{NP}\right.$ a nefi[ ${ }_{\mathrm{V}} \mathrm{V}$ koti NP $\left.\left.\left.\left.\left.\left.\mathrm{t}_{\mathrm{San}}\right]\right]\right]\right]\right]\right]$

(iv) a. $\left[\left[_{\mathrm{CP}}\left[\left[_{\mathrm{TP}}\left[{ }_{\mathrm{VP}} \mathrm{NP}\right.\right.\right.\right.\right.$ Zhangsan $\left[{ }_{\mathrm{V}}\right.$, na $\left[{ }_{\mathrm{VP}}\right.$ shenme $\left[{ }_{\mathrm{V}} \mathrm{V}\right.$ qie NP mianbao $\left.\left.\left.\left.]\right]\right]\right]\right]$

b. Zhangsan take what cut bread

b. $\left[{ }_{\mathrm{CP}}\left[{ }_{\mathrm{TP}}\left[{ }_{\mathrm{VP}} \mathrm{NP}\right.\right.\right.$ Zhangsan $\left[{ }_{\mathrm{V}}\right.$ na $\left[{ }_{\mathrm{VP}}\right.$ dao $\left[\mathrm{V}_{\mathrm{V}} \mathrm{V}\right.$ qie NP shenme $\left.\left.\left.\left.]\right]\right]\right]\right]$

Zhangsan take knife cut what

c. ${ }^{*}\left[{ }_{\mathrm{CP}}\right.$ Spec Shenme ${ }_{\mathrm{TP}}\left[{ }_{\mathrm{VP}} \mathrm{NP}\right.$ Zhangsan $\left[{ }_{\mathrm{V}}\right.$. na ${ }_{\mathrm{VP}} \mathrm{t}_{\text {shenme }}\left[{ }_{\mathrm{V}} \mathrm{V}\right.$ qie NP mianbao $\left.\left.\left.\left.]\right]\right]\right]\right]$

what Zhangsan take cut bread

d. $*\left[_{\mathrm{CP}}\right.$ Spec Shenme $\left[{ }_{\mathrm{TP}}\left[{ }_{\mathrm{VP}} \mathrm{NP}\right.\right.$ Zhangsan $\left[{ }_{\mathrm{V}}\right.$, na $\left[_{\mathrm{VP}}\right.$ dao $\left[{ }_{\mathrm{V}} \mathrm{V}\right.$ qie $\left.\left.\left.\left.\left.\mathrm{NP} \mathrm{t}_{\text {shenme }}\right]\right]\right]\right]\right]$ what Zhangsan take knife cut

As LeFEBVRe (1991) points out, while coordinate or subordinate clauses remain islands for extraction, serial verb constructions do not. In other words, it is always possible to extract the objects of both verbs. It is noteworthy that the complement cannot be extracted together with the verb which assigns Case to it.

(v) a. *na dao, Zhangsan qie mianbao

take knife Zhangsan cut bread

b. *qie mianbao, Zhangsan na dao

cut bread Zhangsan take knife 


$$
\begin{aligned}
& \left.{ }_{V P} \text { NP Koku }\left[V, V \text { só }\left[_{V P} N P \text { aty }\left[V_{V} \text { V xo NP Asiba }\right]\right]\right]\right] \\
& \text { Koku use stick beat Asiba } \\
& \left.\left.\left.{ }_{V P} N P \text { Olú }\left[V_{V}, V \text { lu [ }{ }_{V P} \text { NP màálù }{ }_{i}{ }_{V}, V \text { kú NP }\right]\right]\right]\right] \\
& \text { Olú beat cow die }
\end{aligned}
$$

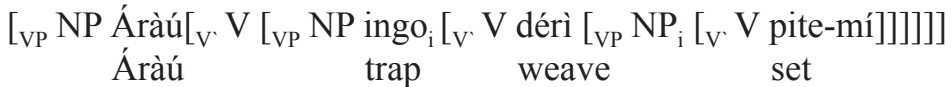

$$
\begin{aligned}
& {\left[{ }_{V P} N P \text { Bóló }\left[{ }_{V}, V \text { sè }\left[_{V P} N P \text { eran }{ }_{i}\left[V_{V} V \text { tà } N_{i}\right]\right]\right]\right]} \\
& \text { Bóló cook meat sell }
\end{aligned}
$$

As (20) shows, SVCs have the following characteristics: 1) when two verbs function as the predicates and share the same object, there is no empty predicate position in the syntactic structure; 2) when a noun intervenes between the two verbs and functions as the object of V1 and the semantic subject of V2, there is no empty predicate position in the syntactic structure; 3 ) if the two verbs govern two different nouns and assign different theta-roles to them, there is no empty predicate position in the syntactic structure; V1 represents instrument or manner, and its object can function as a circumstantial argument, and hence VP1 is equal to a prepositional phrase, similar to SVCs in Chinese; 4) when the two verbs share the same noun, V1 assigning accusative Case to the noun, the relationship between V1 and the noun is VO while the relationship between V2 and the noun is subject-predicate, which in underlying structure is $\mathrm{VO}$, as a result of which there is no empty predicate position in the syntactic structure; 5) V1 c-commands V2 asymmetrically; 6) the verbs in SVCs do not necessarily share the same object, but they must share the same subject, i.e. the action or behavior of the verbs is made by the same agent; 7) the phrase structure can be VO, OV, manner-goal, adjunction-action, positive-negative, and the syntactic-semantic relationship can be combination, modifier-head, and subject-predicate.

In view of its constituents, an SVC can contain only a noun subject and two head verbs or more constituents, for example, one or two objects. According to word order and constituency, SVCs can fall into the following seven types: ${ }^{12}$

${ }^{12}$ We argue that the logical-semantic relation between V1 and V2 can be regarded as modification, which is a relation of c-command. C-command which is base-generated determines the relation between the modifier and the modified. V2 serves the function of purpose, manner, means, and so on. Furthermore, V1 (VP1) precedes V2 (VP2) because of the asymmetrical c-command.

(i) a. Zhangsan qi de zhanqilai pai zhuozi.

Zhangsan angry DE stand-up slap table

'Zhangsan was so angry that he stood up and slapped the table.'

b. *Zhangsan qi de pai zhuozi zhanqilai.

Zhangsan angryDE slap table stand-up

(ii) a. Zhangsan qishen rangzuo.

Zhangsan stand-up offer-seat

'Zhangsan stood up and offered his seat.'

b. *Zhangsan rangzuo qishen.

Zhangsan offer-seat stand-up

(iii) a. Zhangsan shang yiyuan kan bing.

Zhangsan go hospital see disease

'Zhangsan went to hospital and saw a doctor.'

b. *Zhangsan kan bing shang yiyuan.

Zhangsan see disease go hospital 


$\begin{array}{ll}\text { (21a) } & \mathrm{S}+\mathrm{V} 1+\mathrm{V} 2 \\ \text { (21b) } & \mathrm{S}+\mathrm{V} 1+\mathrm{O}+\mathrm{V} 2 \\ \text { (21c) } & \mathrm{S}+\mathrm{O}+\mathrm{V} 1+\mathrm{V} 2 \\ \text { (21d) } & \mathrm{S}+\mathrm{V} 1+\mathrm{V} 2+\mathrm{O} 2 \\ \text { (21e) } & \mathrm{S}+\mathrm{V} 1+\mathrm{O} 1+\mathrm{V} 2+\mathrm{O} 2 \\ \text { (21f) } & \mathrm{S}+\mathrm{O} 1+\mathrm{V} 1+\mathrm{O} 2+\mathrm{V} 2 \\ \text { (21g) } & \mathrm{S}+\mathrm{O} 2+\mathrm{V} 2+\mathrm{V} 1\end{array}$

(21a) is a basic structure, of which V1 and V2 are followed by no object, as shown in (22). In (21b), V1 and V2 share the same noun object, and V2 can be a transitive verb or unaccusative verb, but V2 is causative, as shown in (23). In (21c), V1 and V2, which share the same object, form a compound with the structure of verb-complement. They govern the preceding noun and assign accusative Case to it, as shown in (24). In (21d), V1 is an intransitive verb and V2, a transitive verb, governs its following noun and assigns accusative Case to it, as shown in (25). In (21e), V1 and V2 govern different nouns respectively. VP1 made up of V1O1 governs VP2 made up of V2O2, and VP2 functions as the complement of VP1, as shown in (26). In (21f), V1 and V2 also govern their preceding nouns and assign accusative Case to the nouns respectively, as shown in (27). In (21g), V1, which is a governing verb, is followed by no object. Its occurrence precedes $\mathrm{V} 2$, which governs $\mathrm{O} 2$ and is before V1 in terms of linear order, which gives rise to a surface structure disobeying the Temporal Iconicity, as shown in (28).

(22a) ta shangchuan shuijiao

Chinese

3SG ascend-bed sleep

'He went to bed.'

(22b) We'll go see.

(23a) Olú lu màálù kú

Olu beat cow die

'Olu beat the cow dead.'

Yoruba (BAKER 1989)

(23b) Bóló sè eran tà

Bolo cook meat sell

Nupe (LORD 1974)

'Bolo cooked meat and sold it.'

(24a) Chelswu-ka chayksang-ul twutulki-e pwusi-ess-ta Korean (Li 2007)

Chelswu-NOM table-ACC beat break-PST-DEC

'Chelswu broke the table.'

(24b) John Mary-ra pruk-an Bill plap-an

Miskito (Li 1991)

John Mary-ACC beat Bill run-PST

'John beat Mary, and Bill ran.'

(24c) Áràú ingo dérì pite-mí.

3SG trap weave set-PST

Ijo (WiLliamson 1965)

'She wove a trap and set it.' 
(26a) ta jueding huilai jie wo

Chinese 3SG decide return meet $1 \mathrm{SG}$

'He decided to come back to meet me.'

İywi awá ótsi ikù utsì

child take stick close door

Yatye (STAHLKe 1970)

'The child took the stick and closed the door.'

Koku só aty xo Asiba.

Koku take stick beat Asiba

'Koku took the stick and beat Asiba.'

Kofi naki Amba kiri en

Kofi hit Amba kill her

'Kofi struck Amba dead.'

Áràú zu-ye ákì buru teri-mí

3SG basket take potato cover-PST

'She took the basket and covered the potato.'

$\mathrm{yu}^{33}$ thi $^{21} \mathrm{şu}^{33} \quad \mathrm{li}^{21}$

$1 \mathrm{SG} 3 \mathrm{SG}$ search go

'I go and look for him.'

the: fa xsə guə topu

3SG clothes new wear like

'He likes to wear new clothes.'

$\mathrm{ya}^{33} \mathrm{thu}^{33} \mathrm{ku}^{33} \mathrm{fei}^{33} \quad \mathrm{so}^{24}$

1SG collar embroider learn

'I learn to embroider the collar.'

$\mathrm{ya}^{55} \mathrm{xo}^{31} \mathrm{t}_{6 \mathrm{a}} \mathrm{li}^{31}$

$1 \mathrm{SG}$ rice cook go

'I go and cook rice.'

Kazhuo (DAI \& QIU 2008)

$\mathrm{ya}^{31} \mathrm{ma}^{21} \mathrm{za}^{53} \quad \mathrm{te}^{31} \mathrm{ga}^{53}$

1SG soldier be want

'I want to be a soldier.'
Qiang (DAI \& QIU 2008)

Hani (DAI \& QIU 2008)

Kwa (LeFEbVRe 1991)

Ijo (WILLIAMSON 1965)

Yi (DAI \& QIU 2008)

Sranan (BAKER 1989)

Lahu (DAI \& QIU 2008)

In fact, (21c) and (21d), (21e) and (21f) as well as (21g) reflect two different types of word order: SVO and SOV. Word order just changes the linear order between the verb and the object, but it does not influence the syntactic and semantic relations between them. (22) (28) all belong to the so-called narrow SVC, i.e. the construction includes only the sequence of verbs or verb phrases but excludes SVCs with the intervention of other constituents. In terms of syntactic structure, narrow SVCs fall into four categories: 1) V1 and V2 are closely linked and followed by no object; 2) V1 is followed by an object, whereas V2 is followed by no object; 3) V1 is followed by no object; 4) both V1 and V2 are followed by objects. 
Broad SVCs include not only narrow SVCs but also a sequence of prepositional phrase and verbs, SVCs in which there is a phonetic pause between the verbs, SVCs in which there are intervening constituents such as conjunctions, adverbs, auxiliaries, and connecting words, and SVCs whose subject is an agent or patient or an agent-patient complex. If the object is excluded, there are two most basic types of SVCs, i.e. S+V1+V2 and S+V2+V1. In the two types of SVCs, the former follows the Temporal Iconicity while the latter does not. In other words, under most circumstances, verbs in SVO-type SVCs follow the Temporal Iconicity (YANG 2009). SOV-type SVCs also follow the Temporal Iconicity under most circumstances, and only a small portion of SVCs representing government disobey this principle. DAI \& QIU (2008) argues that this is due to the fact that the order of these languages is SOV. The Temporal Iconicity is more applicable to SVO languages than SOV languages. Since the characteristics of word order are predominant, when cognition and word order are inconsistent, the characteristics of word order will be followed while the Temporal Iconicity will be disobeyed. However, Korean, Miskito, and Ijo, which are SOV languages, follow the Temporal Iconicity. It is self-evident that whether SVCs follow the Temporal Iconicity is irrelevant to linguistic typology. This testifies that DAI \& QIU'S (2008) conclusion is open to discussion. In fact, SVCs always follow the Temporal Iconicity, regardless of the types of languages. ${ }^{13}$ This point will be discussed in detail below.

It is noteworthy that in SVCs there exists asymmetrical c-command between V1 and V2 (BARSS \& LASNIK 1986), i.e. V1 must c-command V2. ${ }^{14}$ The most basic semantics denoted by SVCs is semantic transference, and hence V1 and V2 form a semantic chain, as a result of which the whole structure is generated dynamically (СНомSKY 2000, 2001, 2004, 2005,

${ }^{13}$ CARSTens (2002) addresses SVCs in VO versus OV languages and talks about the Temporal Iconicity, which she rejects as a force in syntactic relations. Semantic compositionality requires the construction of coherent sub-events like (ia). In truly symmetrical head-final syntax it would be the mirror image order (ib), which she claims is unattested.

(i) a. [take [basket [cover yam]]]

b. ?[[[yam cover] basket] take]]

Semantic compositionality rules impossible the hierarchical organizational below for the typical word order in SVCs of an OV language as shown in (ii).

(ii)

*[[[take basket $]$ cover $]$ yam $]]$

Hence the same verb must be V1 in hierarchical structure in both head-initial and head-final languages. When we see the construction "basket take yam cover" in a language like Ijo, it shows us that the structure is underlyingly the same as in the OV languages (due to KAYNE's (1994) antisymmetry of syntax) but OV languages involve leftwards movement of the objects across the verbs to local Spec positions.

(iii) $\quad\left[\right.$ basket $_{\mathrm{i}}$ take $\left[\mathrm{t}_{\mathrm{i}}\left[\right.\right.$ yam $_{\mathrm{j}}$ cover $\left.\left.\mathrm{t}_{\mathrm{j}}\right]\right]$

${ }^{14}$ CARSTENS (2002) argues that strict head-final surface order derives from underlying left-headedness in Ijo. A word order anomaly in Ijo SVCs strongly suggests this, and left-to-right asymmetric c-command among internal arguments of SVCs confirms it. The anomaly is universal among surface right-headed languages with SVCs, indicating that deep left-headedness is universal, as antisymmetry theory predicts (KAYNE 1994). Assuming complements are in Specs, and that a light verb $v$ selects every VP (СНOMSKY 1999), she derives VOVO from OVOV by two instances of V-to- $v$ movement. She proposes that the main verb is higher in the structure than the light verb. This proposal is made to account for the cross-linguistic fact that the order of verbs in verb-verb constructions in OV languages is not the mirror image of their order in VO languages (MUYSKEN 1988). In CARSTENS' (2002) analysis, in both OV and VO languages, the first verb is higher in the structure than the second and selects the second $v \mathrm{P}$. Word order differences between $\mathrm{OV}$ and $\mathrm{VO}$ are obtained simply by $\mathrm{V}$ to $v$ movement of both verbs in the case of VO languages. 
2007). In the framework of the Minimalist Program, syntactic derivation is conducted by phase and by means of merge. A simple sentence is composed of two phases, i.e. $\mathrm{CP}$ and $v \mathrm{P}$. Its logical form is shown as follows:

\section{$[\mathrm{CP}[\mathrm{TP}[v \mathrm{P}[\mathrm{VP}]]]]$}

In terms of linear structure, syntactic derivation is conducted from left to right, i.e. the phase $v \mathrm{P}$ is generated first, and then the phase $\mathrm{CP}$ is generated, which forms a structure as shown in (29). According to VP Internal Subject Hypothesis (HoRnsteIn et al. 2005), the subject is generated within $v \mathrm{P}$, and it moves from [Spec $v \mathrm{P}]$ to [Spec TP]. The arguments in SVCs undergo A-movement, forming a chain which gives rise to the interpretation that the same argument is involved in the events. The "shared" arguments in SVCs are copies left behind by A-movement, thus forming a chain, rather than the lexical insertion of an element such as pro. All verbs involved in SVCs must merge cyclically, including verbs and their arguments. Each argument then identifies the subsequent events expressed by the verbs in SVCs. It is claimed that the arguments in SVCs move for the purpose of identifying relevant features: the internal argument raises to [Spec AspP] to identify the feature [Telic]. The external argument raises to [Spec TP] to satisfy the requirement of the features of EPP/Case. In this way, we can account for the interpretation of the same arguments in relation to both verbs in SVCs, even though one set of arguments is apparently missing. Furthermore, these empty positions cannot be occupied by any lexical element (CHOI 2003). Hence the argument structure of SVCs can be analyzed as follows:

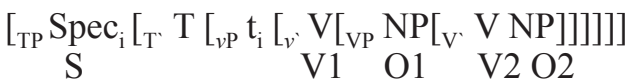

$$
\begin{aligned}
& {\left[{ }_{T P} \operatorname{Spec}_{i}\left[\left[_{T^{\prime}} T{ }_{{ }_{v P}} \mathrm{t}_{\mathrm{i}}\left[{ }_{v^{\prime}} \mathrm{V}\left[{ }_{\mathrm{VP}} \mathrm{NP}\left[{ }_{\mathrm{V}^{\prime}} \mathrm{V}\left[{ }_{\mathrm{VP}} \mathrm{NP}\left[{ }_{\mathrm{V}^{\prime}} \mathrm{V}\right]\right]\right]\right]\right]\right]\right]\right]} \\
& \mathrm{S} \\
& \mathrm{O} 1 \quad \mathrm{~V} 1 \quad \mathrm{O} 2 \mathrm{~V} 2
\end{aligned}
$$

(30a) is the argument structure of SVO-type SVCs. The subject is base-generated within $v$ P. It moves to [Spec TP] in order to satisfy the requirement of the features of EPP. O1 and $\mathrm{O} 2$ are in [NP $\left.v^{\prime}\right]$ and [NP $\left.\mathrm{V}^{\prime}\right]$ respectively, and $\mathrm{V} 1$ and $\mathrm{V} 2$ are in [ $\left.\mathrm{V} v^{\prime}\right]$ and [ $\left.\mathrm{V} \mathrm{V}^{\prime}\right]$ respectively. (30b) is the argument structure of SOV-type SVCs. The subject is also base-generated within $v \mathrm{P}$, and it moves to [Spec TP] so as to satisfy the requirement of the features of EPP. $\mathrm{O} 1$ and $\mathrm{O} 2$ are in outer [NP VP] and inner [NP VP] respectively, and V1 and V2 are in [V $v^{\prime}$ ] and [VV'] respectively. As far as SVCs in Yi, Qiang, Kazhuo, and Hani, which do not follow the Temporal Iconicity, are concerned, their argument structure is different, as shown in (31).

$$
\begin{aligned}
& {\left[{ }_{\mathrm{TP}} \mathrm{Spec}_{\mathrm{i}}\left[{ }_{\mathrm{T}^{\prime}} \mathrm{T}\left[{ }_{v \mathrm{P}} \mathrm{t}_{\mathrm{i}}\left[{ }_{v^{\prime}} \mathrm{V}\left[{ }_{\mathrm{VP}} \mathrm{NP}\left[{ }_{\mathrm{V}^{\prime}} \mathrm{V}\left[{ }_{\mathrm{VP}} \mathrm{NP}\left[{ }_{\mathrm{V}^{*}} \mathrm{~V}\right]\right]\right]\right]\right]\right]\right]\right]} \\
& \begin{array}{llll}
\mathrm{S} & \mathrm{O} 2 & \mathrm{~V} 2 & \mathrm{~V} 1
\end{array}
\end{aligned}
$$

The subject, which is base-generated within the inner VP, governs V1. It moves all the way to [Spec TP] in order to satisfy the requirement of the features of EPP. V1 and V2 are in inner [ $\left.\mathrm{VV}^{\prime}\right]$ and outer $\left[\mathrm{V} \mathrm{V}^{\prime}\right]$ respectively, and $\mathrm{O} 2$ is in [Spec $\left.\mathrm{VP}\right]$.

As mentioned above, the subject of SVO-type SVCs is base-generated within $v \mathrm{P}$. It moves to [Spec TP] in order to satisfy the requirement of the features of EPP. O1 and O2 are in [NP $\left.v^{\prime}\right]$ and [NP $\left.\mathrm{V}^{\prime}\right]$ respectively, and $\mathrm{V} 1$ and $\mathrm{V} 2$ are in [V $\left.v^{\prime}\right]$ and [ $\mathrm{V}^{\prime}$ ] respectively. This structure has two internal arguments and one external argument. VP1, which is made up of V1 and O, always precedes VP2, which is made up of V2 and O2, and hence VP1 
c-commands VP2. V1 and V2 assign different theta-roles to O1 and O2 respectively. V1 represents instrument and manner, and its object functions as a circumstantial argument. Hence VP1 is commensurate with PP. When there are two verbs sharing the same noun object in a sentence, V1 assigns nominative Case to the noun and the relation between them is VO. The relation between V2 and the noun is subject-predicate, but in underlying structure the relation between them is VO. V1 c-commands V2, and hence the relation between them is asymmetrical. The verbs in SVCs do not necessarily share the same object, but they must share the same subject, i.e. the actions are taken by the same agent. The internal structure of the phrase may be VO, OV, manner-aim, circumstance-action, or affirmation-negation. There exist such semantic relations as coordination, modification or subject-predicate between them. ${ }^{15}$

$$
\begin{aligned}
& {\left[{ }_{T P} \mathrm{WO}_{\mathrm{i}}\left[{ }_{\mathrm{T}}, \mathrm{T}\left[_{v \mathrm{P}} \mathrm{t}_{\mathrm{i}}\left[_{v} \text { shangchuan }\left[{ }_{\mathrm{VP}} \mathrm{NP}\left[{ }_{\mathrm{V}^{\prime}} \text { shuijiao }\right]\right]\right]\right]\right]\right.} \\
& 1 \mathrm{SG} \\
& \text { ascend-bed }
\end{aligned}
$$

Chinese

'I go to bed.'

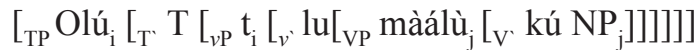

$$
\begin{aligned}
& \text { Olu beat cattle die }
\end{aligned}
$$

'Olu killed the cattle.'

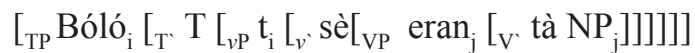

$$
\begin{aligned}
& \text { Bolo cook meat sell }
\end{aligned}
$$

$$
\begin{aligned}
& \left.\left[\text { İywi }_{\mathrm{T}}\left[{ }_{\mathrm{T}} \mathrm{T}\left[_{\nu \mathrm{P}} \mathrm{t}_{\mathrm{i}}\left[_{v^{\prime}} \text { awá }{ }_{\mathrm{VP}} \text { ótsi }\left[{ }_{V} \text { ikù utsì }\right]\right]\right]\right]\right]\right] \\
& \text { child take stick close door } \\
& \text { 'The child used the stick to close the door.' }
\end{aligned}
$$

As (32) shows, VP1, which functions as a SV phrase, governs VP2, which is in a subordinate position. And VP2 is commensurate with aim argument or result argument. Second, $\mathrm{V} 1$ and V2 share the same object, and $\mathrm{O} 1$ or $\mathrm{O} 2$ can occur covertly. If V2 is an intransitive verb, it is causative. ${ }^{16}$ Third, V1 and V2 govern different noun objects $\mathrm{O} 1$ and $\mathrm{O} 2$, and $\mathrm{O} 1$ is also the manner object of $\mathrm{V} 2$.

Similarly, the subject of SOV-type SVCs is also base-generated within $v \mathrm{P}$, and it moves to $[\mathrm{Spec} \mathrm{TP}]$ in order to satisfy the requirement of the features of EPP. O1 and $\mathrm{O} 2$ are in outer [NP VP] and inner [NP VP] respectively, and V1and V2 are in [V $\left.v^{\prime}\right]$ and [V V'] respectively, as illustrated in (33).

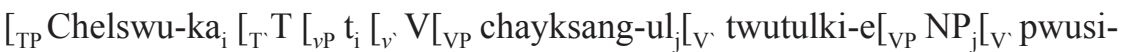

$$
\begin{aligned}
& \text { Chelswu-NOM table-ACC beat break- } \\
& \text { ess-ta]]]]]]]] } \\
& \text { PST-DEC }
\end{aligned}
$$$$
\text { 'Chelswu broke the table.' }
$$

${ }^{15}$ Semantically, SVCs can be regarded as the result of deletion of the conjunction "and" in "V1 and V2". Between A and B there exist subordinate relations of condition, purpose, and cause-effect. In this case, V2's interpretation depends upon V1's interpretation.

${ }^{16}$ Miskito is more complex. If $\mathrm{V} 2$ functions as an unaccusative verb, it is causative. It assigns a theta-role to the preceding NP2, and the whole VP2, which is c-commanded by VP1, represents result. In other words, VP2 is part of the syntactic system, and its patient theta-role is assigned by VP1. 


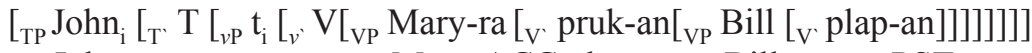

$$
\begin{aligned}
& \text { John Mary-ACC beat Bill run-PST }
\end{aligned}
$$

$$
\begin{aligned}
& {\left[{ }_{T P} \text { Áràú }_{\mathrm{i}}\left[{ }_{T}, \mathrm{~T}\left[_{v \mathrm{P}} \mathrm{t}_{\mathrm{i}}\left[_{v^{\prime}} \mathrm{V}\left[_{\mathrm{VP}} \text { ingo }_{\mathrm{j}}\left[{ }_{V^{\prime}} \text { dérì }\left[{ }_{\mathrm{VP}} \mathrm{NP}_{\mathrm{j}}\left[_{V^{\prime}} \text { pite-mí }\right]\right]\right]\right]\right]\right]\right]\right.} \\
& \text { 3SG net knit set-PST }
\end{aligned}
$$

As (33a) shows, V1 and V2 share the same object, but the object precedes V1 and V2. The subject governs VP1 directly, and VP1 governs VP2, which is commensurate with result argument.

In Yi, Qiang, Kazhuo, Hani, and Lahu, SVCs, which represent coordination, modification and addition, follow the Temporal Iconicity. But those which represent government do not follow the Temporal Iconicity. The argument structure of data in (28) is shown as (34).

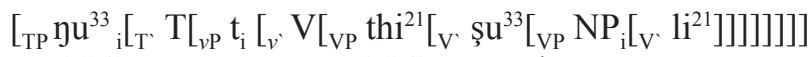

$$
\begin{aligned}
& 1 \mathrm{SG} \quad 3 \mathrm{SG} \text { search go }
\end{aligned}
$$

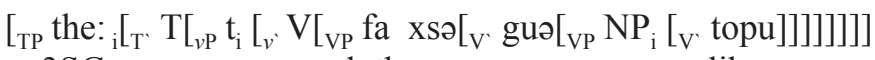

$$
\begin{aligned}
& \text { 3SG clothes new wear like }
\end{aligned}
$$

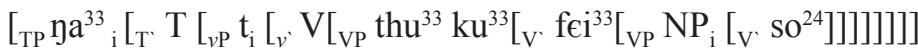

$$
\begin{aligned}
& 1 \mathrm{SG} \text { collar embroider learn }
\end{aligned}
$$

'I learn to embroider the collar.'

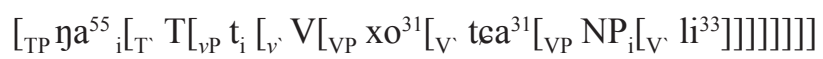$$
1 \mathrm{SG} \text { rice cook go }
$$

'I went to cook rice.'

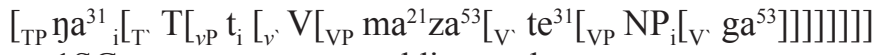

$$
\begin{aligned}
& 1 \mathrm{SG} \text { soldier be want }
\end{aligned}
$$

As (34) shows, V1 follows V2 and O2, and V1 represents intention or tendency. The subject is base-generated within the embedded VP. It moves cyclically to [Spec TP]. V1 follows V2, but it still governs V2 and c-commands V2, because V1 and its preceding noun form a subject-predicate relation before they and VP2 form a subordination relation.

VP1 always c-commands VP2 asymmetrically, which is irrelevant to the types of SVCs and the order of V1 and V2. According to Linear Correspondence Axiom (KAYNE 1994: 33) and Principle of Category Order (DAI 2003), if an arbitrary constituent X c-commands another arbitrary constituent $\mathrm{Y}$, and $\mathrm{Y}$ cannot c-command $\mathrm{X}$, the types of structure may be as follows:

$$
\text { V1 c-commands V2. }
$$

V1 c-commands $\mathrm{O}$, and V1O c-commands V2.

V2 c-commands O, and V1 c-commands V2O. 
In view of (35), there is no mutual c-command but asymmetrical c-command between V1 and V2, which can guarantee that V1 is higher than V2 in hierarchical structure and precedes V2 in terms of linear order. Since V2 does not move, V1O c-commands V2. In this case, $\mathrm{O}$ functions as the semantic subject of V2. This hypothesis can give a sound explanation of SVO-type and SVO-type SVCs.

$$
\begin{aligned}
& * \mathrm{~S}+\mathrm{V} 2+\mathrm{V} 1+\mathrm{O} 1 \\
& * \mathrm{~S}+\mathrm{O} 2+\mathrm{V} 1+\mathrm{V} 2 \\
& * \mathrm{~S}+\mathrm{V} 2+\mathrm{V} 1+\mathrm{O} 2 \\
& { }^{*} \mathrm{~S}+\mathrm{V} 1+\mathrm{O} 1+\mathrm{O} 2+\mathrm{V} 2 \\
& * \mathrm{~S}+\mathrm{V} 2+\mathrm{V} 1+\mathrm{O} 1+\mathrm{O} 2 \\
& * \mathrm{~S}+\mathrm{O} 2+\mathrm{V} 1+\mathrm{O} 1+\mathrm{V} 2 \\
& * \mathrm{~S}+\mathrm{O} 2+\mathrm{O} 1+\mathrm{V} 1+\mathrm{V} 2 \\
& * \mathrm{~S}+\mathrm{O} 2+\mathrm{O} 1+\mathrm{V} 2+\mathrm{V} 1
\end{aligned}
$$

The ungrammaticality of the constructions in (36) testifies the correctness of the hypothesis in (35). V c-commands O, and VP1 c-commands VP2. Thus, if V2 moves, it has to move to the position which precedes VP1. If O1 moves, it has to move to the position which precedes $\mathrm{V} 1$. If both $\mathrm{O} 1$ and $\mathrm{O} 2$ move, $\mathrm{O} 1$ moves to the position which precedes $\mathrm{V} 1$ and $\mathrm{O} 2$ moves to the position which precedes $\mathrm{V} 2$. If only $\mathrm{O} 1$ or $\mathrm{O} 2$ moves, the structure will be ungrammatical. This shows that in SVCs, if $\mathrm{V} 1$ governs $\mathrm{O} 1$ and $\mathrm{V} 2$ governs $\mathrm{O} 2, \mathrm{O} 1$ and $\mathrm{O} 2$ must move at the same time in order to generate grammatical constructions. The constituents which are governed or c-commanded can only move to the positions preceding the constituents which govern or c-command them, because they cannot cross over other nodes, or rather, they cannot go beyond the minimal domain of the maximal projection of the structure in which they are, otherwise they would violate Minimalist Link Condition (MLC) (Chomsky 1995: 311). V-movement and O-movement are head movement. The former is verb movement but the latter is argument movement. V is base-generated within VP. It is attracted by $v$, and hence it moves and adjoins to $v$ to form $\mathrm{V}+v$. If $v$ is phonetically empty, it forms $v+\mathrm{e}$. V c-commands O, and VP1 c-commands VP2, which forms SVO-type SVCs. If O moves, SOV-type SVCs are formed. If V2 moves to the position which precedes V1, SOV-type SVCs, which would violate the Temporal Iconicity, are formed. Under this circumstance, V1's transitivity is lost, which can be regarded as ergativization ${ }^{17}$, because it has lost its ability to assign Case. O2 and V2 can move to the position which precedes V1 by means of pied-piping to form SOV-type SVCs. The subject moves to [Spec TP] so as to satisfy the requirement of the features of EPP. Likewise, the object moves to [Spec $v \mathrm{P}]$ so as to satisfy the requirement of the features of EPP. The former checks the feature of T while the latter checks the feature of $v$ P. Verb movement is caused by being attracted by $v$. Both SVO-type and SOV-type SVCs follow the Temporal Iconicity. As far as Tibeto-Burman languages (e.g. Yi, Qiang, Kazhuo, Hani, and Lahu) are concerned, only a small portion of

${ }^{17}$ Ergativization is a syntactic process in which a transitive verb transforms into an intransitive verb. After ergativization, the subject of the verb cannot be the agent, and the accusative Case which the verb can assign disappears. As a result, the verb loses its ability to assign accusative Case to its internal argument. Strictly, intransitivity means that the verb loses its ability to assign accusative Case. 
them representing government do not follow the Temporal Iconicity, which can be soundly accounted for by means of our approach to SVCs. In other words, SVCs, which do not follow the Temporal Iconicity, belong to the class of SOV languages, the deep structure of which still follows the Temporal Iconicity. V2 and O2 are base-generated and then raise and move to generate the surface structure which does not follow the Temporal Iconicity, as shown in (37). The types of SVCs in (28) can be summarized as S+O2+V2+V1, i.e. both $\mathrm{O} 2$ and V2 precede V1. According to our approach to SVCs, the derivation is shown as (37).

$$
\begin{aligned}
& {\left[{ }_{T P} \mathrm{yu}^{33}{ }_{\mathrm{i}}\left[_{\mathrm{T}^{\prime}} \mathrm{T}\left[{ }_{\mathrm{vP}} \mathrm{t}_{\mathrm{i}}\left[\left[_{\mathrm{v}^{\prime}} \mathrm{V}\left[\mathrm{VP}_{\mathrm{VP}} \mathrm{thi}^{21}\left[\mathrm{~V}_{\mathrm{V}} \mathrm{şu}^{33}\left[\mathrm{VP}_{\mathrm{VP}} \mathrm{NP}_{\mathrm{i}}\left[\mathrm{V}_{\mathrm{V}} \mathrm{li}^{21}\right]\right]\right]\right]\right]\right]\right]\right]\right.} \\
& \text { 1SG him search go } \\
& \text { 'I went to look for him.' }
\end{aligned}
$$

In the light of the approach to SVCs proposed above, V1 is the major predicate, bearing tense-aspect markers, which occur covertly. ${ }^{18}$ According to V'-Reanalysis ${ }^{19}$, V' in underlying structure is made up of the verb $l i^{2 l}$ and an ASP bearing covert tense-aspect markers, for $\mathrm{V} 1$ is the major predicate. In this case, $l i^{21}$ raises to the position of the empty verb as a head to generate $\mathrm{S}+\mathrm{V} 1+\mathrm{O} 2+\mathrm{V} 2$. If we further observe (28), we will find that when $\mathrm{O} 1$ is empty, $\mathrm{O} 2$ can move to this position in order to receive a theta-role. Accordingly, V2 can move to the position which precedes V1 so as to assign accusative Case ${ }^{20}$ to $\mathrm{O} 2$. In general, V1 only governs O1, and VP1 governs VP2. If bare V1 governs VP2, SOV-type SVCs will take the form of $\mathrm{S}+\mathrm{O} 2+\mathrm{V} 2+\mathrm{V} 1$. Thus, the conditions of generation of SVCs which do not follow the Temporal Iconicity can be summarized as (38).

${ }^{18}$ V1 in Chinese SVCs can be followed by aspect marker complements, but V1 in Tibeto-Burman SVCs cannot. The complement can only be inserted between V1 and V2, and hence it is commensurate with a conjunction (DAI \& QIU 2008). For example,

(i)

$$
\begin{aligned}
& \mathrm{Ivu}^{55} \text { mĕ}^{21} \text { non }^{51} \quad \mathrm{e}^{51} \\
& \text { see envy (AUX) } \\
& \text { 'see and envy.' }
\end{aligned}
$$

(ii) $\quad \mathrm{kjo}^{35} \mathrm{nak}^{55} \operatorname{mjan}^{31} \mathrm{za}^{55}$

$$
\begin{array}{llll}
\mathrm{ya}^{55} \mathrm{du}^{33} & \mathrm{mi}^{31} \mathrm{kho}^{31} \mathrm{xe}^{31} \mathrm{sa}^{31} \mathrm{a}^{55} \mathrm{ne}^{33} & \mathrm{li}^{33} \\
\text { let's wood cut } & \text { finish }(\mathrm{CONJ}) & \text { go } \\
\text { 'Let's go and cut wood.' } &
\end{array}
$$

It must be pointed out that the statement V1 can bear tense / aspect markers does not imply only V1 can bear tense / aspect markers. V2 also can bear tense / aspect markers. However, it is more common for V1 to bear tense / aspect markers.

(iv) Zhangsan na dao qiele rou.

Zhangsan take knife cut-PST meat

'Zhangsan cut meat by taking a knife.'

${ }^{19} \mathrm{~V}^{\prime}$-Reanalysis: Suppose $\alpha$ is a phrase [ $\left.\mathrm{V}^{\prime} \ldots\right]$, and the phrase has only one lexical category, $\alpha$ can be reanalyzed as $[\mathrm{V} . .$.$] . This condition allows any predicate with only one lexical category to be interpreted as an \mathrm{X}^{0}$ category, and hence it can operate like a simple category. V', which has been reanalyzed, can move to the empty predicate position in the higher layer like a verb head (cf. LARSON 1988; CHENG 1999: 249).

${ }^{20}$ FERGUSON (1996) points out that there is connection between overt object raising and overt verb raising, for the verb checks the object. If the object raises, the verb also raises. 
VP2 precedes VP1, and if and only if O1 is empty, V1 governs VP2.

In SVCs in such languages as Yi, Qiang, Kazhuo, Hani, and Lahu, if O1 is empty, O2 can move to this position, and V2 can move to the position which precedes V1, so that $\mathrm{S}+\mathrm{O} 2+\mathrm{V} 2+\mathrm{V} 1$ can be generated. In contrast, in SVCs in Korean, Miskito, and Ijo, since O1 is not empty, $\mathrm{O} 2$ cannot move to this position, and V2 remains in situ, as a result of which $\mathrm{S}+\mathrm{O} 2+\mathrm{V} 2+\mathrm{V} 1$ cannot be generated. In view of this, SVCs in Yi, Qiang, Kazhuo, Hani, and Lahu, do not follow the Temporal Iconicity in terms of surface structure, but they follow the principle in terms of underlying structure, for the underlying structure of this type of SVCs is still $\mathrm{S}+\mathrm{V} 1+\mathrm{O} 2+\mathrm{V} 2$.

It follows that the approach to SVCs can account for SVO-type and SOV-type SVCs which follow the Temporal Iconicity and SOV-type SVCs whose surface structure violates the Temporal Iconicity. It is self-evident that this approach has three advantages: 1) it can account for SVO-type and SOV-type SVCs in a unified framework and avoid BAKER (1989) and LI's (2007) theoretical self-contradiction; 2) it can give a unified explanation of iconicity-predominant SVCs typical of Chinese and abstractness-predominant SVCs typical of the family of Tibeto-Burman languages; 3) it can give a unified explanation of object-sharing SVCs and non-object-sharing SVCs and solve the problems BAKER (1989) and LI (2007) meet with in accounting for these data.

Up to now, our discussion on the syntactic-semantic relation of SVCs has shown that to set an empty predicate and an empty argument and to assume that VP1 assigns a theta-role to NP3 by means of VP2 cannot only avoid theoretical self-contradiction but also give a sound explanation of SVCs in different languages. However, we haven't answered two questions. What is the argument structure of SOV-type SVCs with double objects? And in what way are the nouns in the sentence assigned theta-roles? We observe the following data first.

$$
\begin{aligned}
& \text { yai }{ }^{33} \underline{n u}^{51} \mathrm{phe}^{755} \mathrm{pă}^{31} \log ^{33} \mathrm{la}^{55} \mathrm{yai}^{51} \mathrm{mi}^{33} \mathrm{mă}^{31} \mathrm{zi}^{33} \mathrm{ja}^{33} \mathrm{să}^{33} \mathrm{yai}^{33} \\
& \text { 1SG mother-ACC-AUX coat one one buy give } \\
& \text { 'I bought my mother a new coat.' }
\end{aligned}
$$

Jingpo (DAI \& QIU 2008)

$$
\begin{array}{llllll}
\mathrm{ya}^{55} \mathrm{a}^{31} \mathrm{ma}^{33} \mathrm{jo}^{755} & \mathrm{phe}^{55} \mathrm{xo}^{31} & \text { t6hi }^{31} & \mathrm{xo}^{55} & \mathrm{\gamma y}^{55} & \mathrm{bi}^{31} \\
\text { 1SG mother(ACC-AUX) coat } & \text { one } & \text { one } & \text { buy } & \text { give } \\
\text { 'I bought my mother a new coat.' } & & & &
\end{array}
$$

Hani (DAI \& QIU 2008)

As (39) shows, the two verbs occur in sequence and both the direct object and the indirect object precede the verbs. According to CHOMSKy $(2000,2001)$, language (L) is a derivation process of mapping the feature $[\mathrm{F}]$ onto the representation. L first selects $\mathrm{F}$ from the set of universal features, which make up the lexicon (LEX). Then L selects the lexical array (LA) from LEX and selects the lexical items from LA to constitute lexical subarray (LS) and maps them onto the representation. Derivation by phase can lighten the burden of syntactic computation, for each phase is determined by LA. A nominal phrase has obtained an argument role in LA, and the order of merge is regulated and controlled by thematic hierarchy. Headed functional categories have strong nominal features, which check the feature of the indirect object D. Hence the derivation of SOV-type SVCs is shown as (40). 


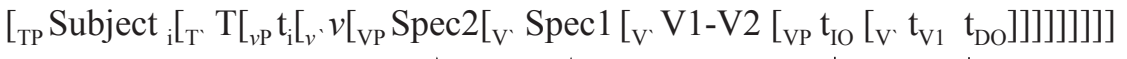

V1 merges with the direct object to form $\mathrm{V}$, which merges with the indirect object to form VP, to license the two internal arguments. Then V1 adjoins to V2 to form V1-V2. Now there are four uninterpretable features: the $\varphi$ feature of V1-V2, the strong nominal feature of V1-V2, the structural Case of the indirect object, and the inherent Case of the indirect object. V1-V2 checks agreement against the two objects and erases the features other than the strong nominal feature of V1-V2. According to the Multiple Specifier Structure proposed by CHOMSKY (1995), the direct object moves to Spec1 to check the strong nominal feature of V1-V2, and the indirect object moves to Spec2 to check agreement against V1-V2. And the external argument moves to Spec2 to license its role. In this case the derivation of the first phase is completed, and only the features of the external argument have not been checked. Therefore computation continues. $\mathrm{T}$ is extracted from LA and merges with VP, which gives rise to four uninterpretable features: the feature $[-\mathrm{V}]$ of $\mathrm{T}$, the $\varphi$ feature of $\mathrm{T}$, the features of EPP, and the strong nominal features of the external argument. Then $\mathrm{T}$ checks agreement against the subject and attracts it to satisfy the requirement of the features of EPP. Up to now, all the uninterpretable features have been checked, and the whole process of derivation has been completed. The structure generated by means of this derivation satisfies BARSS \& LASNIK's (1986) argument on double object constructions that the indirect object c-commands the direct object asymmetrically. $^{21}$

In terms of syntactic structure, in Chinese SVCs, the head precedes the nonhead, whereas in Korean and Ijo, the head follows the nonhead, for in these languages V2 bears the feature $[+\mathrm{I}]$. It is noteworthy that in Chinese $\mathrm{VC}$ compounds the head precedes the nonhead, whereas in Korean and Ijo VC compounds the nonhead precedes the head, as shown in (41).

$$
\begin{array}{ll}
\text { syntactic structure } & \text { lexical structure } \\
\mathrm{V} 1+\mathrm{V} 2 & \mathrm{~V} 1+\mathrm{V} 2 \\
\text { head }+ \text { nonhead } & \text { head }+ \text { nonhead } \\
\text { nonhead }+ \text { head } & \text { nonhead }+ \text { head } \\
\text { verb }+ \text { complement } & \text { verb }+ \text { complement }
\end{array}
$$

Chinese Korean, Ijo

\footnotetext{
constructions, as illustrated below:

(i) a. I showed Mary herself. (anaphor binding)

b. *I showed herself Mary.

(ii) a. I gave every worker ${ }_{i}$ his $_{\mathrm{i}}$ paycheck. (quantifier binding)

b. *I gave its owner every paycheck $_{\mathrm{i}}$.

(iii) a. Which $\operatorname{man}_{\mathrm{i}}$ did you send his paycheck? (weak crossover)

b. *Whose ${ }_{i}$ pay did you send his ${ }_{i}$ mother?

(iv) a. Who did you give which paycheck? (superiority)

b. * Which paycheck did you give who?

(v) a. I showed each man the other's cocks. (each... the other)

b. *I showed the other's friend each man.

(vi) a. I showed no one anything. (negative polarity items)

b. *I showed anyone nothing.
}

${ }^{21}$ BARSS \& LASNIK (1986) observe that there are six kinds of asymmetry between N1 and N2 in double object

There is a lot of much more recent work on c-command relations in double object constructions, with refined conclusions about their structure. For more recent perspectives, see ANAGNostopoulou (2003), BeCK \& JoHNSON (2004), EMONDS \& OstLer (2005), He (2009), BRUENING (2010), among many others. 
If we observe (41) in terms of aspect markers, semantic relationship and word order, we will obtain more plentiful syntactic-semantic information as shown in (42).

$\begin{array}{lll}\text { syntactic structure } & \text { lexical structure } & \text { word order } \\ \mathrm{V} 1+\mathrm{V} 2 & \mathrm{~V} 1+\mathrm{V} 2 & \\ \text { head }[+\mathrm{I}]+\text { nonhead}[-\mathrm{I}] & \text { head }[+\mathrm{I}]+\text { nonhead }[-\mathrm{I}] & \text { SVO } \\ \text { nonhead[-I] + head }[+\mathrm{I}] & \text { non-head[-I]+ head[+I] } & \text { SOV } \\ \text { verb }+ \text { complement } & \text { verb }+ \text { complement } & \end{array}$

Chinese Korean, Ijo

As (42) shows, syntactic structure is consistent with lexical structure and corresponds to word order. In SVO languages the head precedes the nonhead while in SOV languages the nonhead precedes the head. In SVO-type SVCs the head of VC compounds precedes the nonhead while in SOV-type SVCs the nonhead precedes the head. In other words, in SOV lexicon the generation of VC compounds does not trigger head movement. Instead, the head remains in situ. It follows that in SOV languages verb aspect markers cannot trigger head verb movement. If we further observe the syntactic structure and lexical structure of SVO and SOV languages, we will find that V1 carries semantic weight, and V2 povides supplementary information, including result, purpose, state of affairs, etc. Hence, V1+V2 is equal to V1+C(omplement), i.e. $\mathrm{VC} .{ }^{22}$ In SOV languages the feature $[+\mathrm{I}]$ of $\mathrm{V} 2$ does not trigger $\mathrm{V} 2$ movement. Instead it remains in situ order to satisfy both the requirement of word order of SOV languages and the requirement of the Temporal Iconicity. V2's feature weakens or is partially absorbed by V1, as a result of which V-C(omplement) SVCs are formed. Similarly, in SVO languages V1 carries semantic weight, and V2 functions as a complement, providing supplementary information. In this case a verb-complement construction is formed. The difference between the two types of languages lies in that in SVO languages semantic weight and syntactic weight are consistent, as a result of which syntactic and lexical structure are consistent. In contrast, in SOV languages semantic weight and syntactic weight are inconsistent, but due to the requirement of the conceptual-semantic system and the syntactic system as well as the Temporal Iconicity, semantic structure and deep syntactic structure are consistent though they may differ in surface structure (cf. YANG 2009). The above conclusions can be summarized as follows:

$$
\begin{aligned}
& \text { syntactic / lexical structure: }\left[_{\mathrm{VP}} \mathrm{V} 1\left[_{\mathrm{V}}, \mathrm{V} 2\right]\right] \\
& \text { semantic relationship: } \mathrm{V}+\mathrm{C}(\mathrm{omplement}) \\
& \text { syntactic / lexical structure: } \left.*{ }_{\mathrm{VP}}\left[{ }_{\mathrm{V}}, \mathrm{V} 2\right] \mathrm{V} 1\right] \\
& \text { semantic relationship: C(omplement)+V } \\
& \text { syntactic / lexical structure: } \left.*{ }_{\mathrm{VP}} \mathrm{V} 2\left[{ }_{\mathrm{V}} \mathrm{V} 1\right]\right] \\
& \text { semantic relationship: C(omplement)+V }
\end{aligned}
$$

${ }^{22}$ DAI \& QIU (2008) point out that in terms of grammatical of relationships of coordination, modification, addition, and government, the grammaticalization of SVCs in Tibeto-Burman and Chinese mainly occurs in the complement of V2, for in V-C(complement) SVCs the stress falls on V1, and hence V2 tends to grammaticalize, its concrete sense transforming into abstract sense. Take the verb "see" for example. In Tibeto-Burman and Chinese, if placed behind another verb, it generally expresses the meaning "try", which functions as an additional remark for the verb, such as $j u^{55}$ in Leqi, $k o t^{13}$ in Menba of Cangluo, and $t \varepsilon^{44}$ in Jinuo. The verb "die", placed behind another verb, expresses the extremity of the preceding action or behavior, which is equal to "extremely", for example, $s i^{33}$ in Jingpo, $s i^{55}$ in Hani, and $s i^{33}$ in Lahu. The verb "eat", placed behind another verb, grammaticalizes to express "the acquisition" of the action or behavior, for example, $\int a^{55}$ in Jingpo and $d z a^{31}$ in Hani. In a word, V2 in SVCs tends to grammaticalize to function as a complement. 
(43), as a minimal summarization of SVO-type and SOV-type SVCs, can take scope over syntactic structure and VC compounds of SVCs. It can be inferred from (43) that V1 c-commands V2 asymmetrically but not vice versa.

According to (35), there is no mutual c-command but asymmetrical c-command between V1 and V2, which can guarantee that V1 is superior to V2 syntactically and prior to V2 linearly. Since V2 does not move, V1O c-commands V2, and hence O functions as the semantic subject of V2. In this case SVCs in Nupe and Ijo can be accounted for in a unified framework and BAKER (1989) and LI's (2007) inconsistency in theoretical analysis can be avoided.

$$
\begin{aligned}
& \begin{array}{c}
{\left[\mathrm{VP} V 1 \text { sè }\left[\mathrm{NP}_{\mathrm{NP}} \operatorname{eran}_{\mathrm{i}}\left[\mathrm{V}_{\mathrm{V}} \mathrm{V} 2 \text { tà } \mathrm{NP}_{\mathrm{i}}\right]\right]\right]} \\
\text { cook meat sell }
\end{array} \\
& \begin{array}{c}
?\left[\mathrm{VP}_{\mathrm{V}} \mathrm{V} 1 \text { sè } \mathrm{NP}\right. \\
\text { cook mean[ } \mathrm{V}^{,} \mathrm{V} 2 \text { tà]] }
\end{array}
\end{aligned}
$$

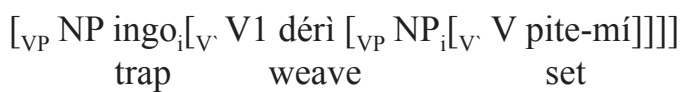

$$
\begin{aligned}
& \begin{array}{c}
\text { ? }{ }_{\mathrm{VP}} \mathrm{NP} \text { ingo V1 dérì[V V2 pite-mí]] } \\
\text { trap weave set }
\end{array}
\end{aligned}
$$

As (44a) shows, V1 c-commands NP asymmetrically. VP1, which is made up of V1NP, c-commands VP2, and NP inside VP2 occurs in the form of an empty argument. (45b) is a multi-branching structure, in which V1 and NP do not c-command each other. If V1 and NP c-command each other, V2 and NP will c-command each other, which would come to a conclusion opposed to facts. It is true of (46). In order to avoid (46b), syntactic structure should take the form in (46a). In underlying structure, V1 c-commands NP and V2 asymmetrically, and NP moves leftward to give rise to surface structure. This treatment can avoid the problems BAKER (1989) meets with in dealing with such data. As mentioned above, BAKER (1989) analyzes these data as (44b) and (45b), in which V1 and NP c-command each other. However, this approach cannot rule (46) out as ungrammatical.

$$
\begin{aligned}
& ?\left[{ }_{\mathrm{VP}} \mathrm{V} 2 \text { tà } \mathrm{NP} \text { eran }\left[{ }_{\mathrm{V}} \mathrm{V} 1 \text { sè }\right]\right] \\
& \text { sell meat cook } \\
& ?\left[\mathrm { VP } _ { \mathrm { VP } } \mathrm { V } 2 \text { pite-mí } \mathrm { NP } \text { ingo } \left[{ }_{\mathrm{V}} \mathrm{V} 1\right.\right. \text { dérì]] } \\
& \text { set trap weave }
\end{aligned}
$$

(46) satisfies neither the requirement of the Temporal Iconicity nor the requirement of the semantic-syntactic system, and hence it is not in accordance with language reality. It follows that there is correspondence between word order, time sequence, conceptualsemantics, and syntactic structure position, and they may not correspond to the bearers of tense-aspect markers. Generally speaking, in SVO languages, there exists complete correspondence between word order, time sequence, conceptual-semantics and syntactic system in terms of lexical structure and syntactic structure, and lexicon corresponds to syntax completely. On the contrary, in SOV languages, there exists incomplete correspondence between word order, time sequence, conceptual-semantics, and syntactic system in terms of lexical structure and syntax. 
Based on this argument, we can provide a unified account of Miskito and Sranan. BAKER (1989) argues that the two verbs in SVCs in (47) describe two events which occur coordinately, and hence they are not SVCs. In contrast, the verbs of SVCs which share the same object describe the events which occur in sequence.

$$
\begin{aligned}
& \text { John Mary-ra pruk-an Bill plap-an. } \\
& \text { John Mary-ACC beat Bill run-PST } \\
& \text { 'John beat Mary and Bill ran.' }
\end{aligned}
$$

Miskito

$$
\begin{aligned}
& \text { Kofi naki Amba kiri en. } \\
& \text { Kofi hit Amba kill 3SG } \\
& \text { 'Kofi beat Amba and killed her.' }
\end{aligned}
$$

Sranan

As (47) shows, the events which the verbs describe are sequential in terms of time, which proves that they are in accordance with the Temporal Iconicity. Furthermore, the two verbs occur in the same sentence, and there is no conjunction intervening between them, which testifies that the two verbs share the same agent. Based on this argument, we can analyze the deep structure of (47) as follows:

$$
\begin{aligned}
& \left.{ }_{V P} \text { NP John }\left[V_{V}, V{ }_{V P} \text { NP Mary }\left[V_{V}, V \text { pruk-an }\left[{ }_{V P} \text { NP Bill[ }\left[V^{*} \text { V plap-an }\right]\right]\right]\right]\right] \\
& \text { John Mary beat Bill run }
\end{aligned}
$$

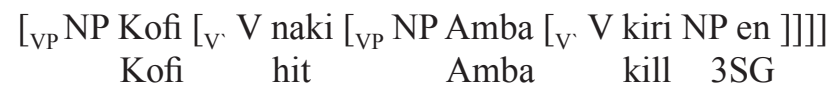

In the light of (48a), V1 governs NP2 and assigns accusative Case to it. V1's maximal projection VP1 assigns Case to NP3. Hence, VP2, which is made up of NP3V2, represents the result of VP1. In other words, V1 is causative. According to VP-Internal Subject Hypothesis (HoRNSTEIN et al. 2005: 81), NP1 John is generated inside VP1 and moves to the highest position of syntactic structure, [Spec, VP], in order to have its Case-feature checked. NP1 governs V1, whereas V1's maximal projection VP1 governs NP3 and V2, and VP2, as VP1's complement, occurs in the sentence. (48b) is similar to (48a). It is noteworthy that $\mathrm{Amba}$ and en refer to the same person, which is in accordance with the Binding Principles and the Anaphora Theory. V1 is prior to V2 both linearly and sequentially, and in addition, it is higher than V2 in terms of syntactic hierarchy, which satisfies syntactic-semantic requirement.

In brief, SVCs can be regarded as V-C(complement) made up of V1 and V2. If V2 moves leftward to V1 and merges with V1, a VC compound, V1+V2, will be generated, i.e. $\mathrm{V} 1+\mathrm{V} 2 \rightarrow \mathrm{VC}$. Take for example, Chinese compounds da-po "beat-break", da-sha "beatkill", chang-zou "sing-walk", and $d a$-si "beat-die". NP following them functions as the shared object of V1V2. V2 is unable to move, for its feature [+I] weakens or has been absorbed by V1, and hence it is in a subordinate position. In this case the types of SVCs may be as follows: 1) V1+NP+V2, i.e. V2 functions as the complement of VP1; 2) V1+V2+NP, i.e. VP2 functions as the complement of $\mathrm{V} 1$; 3) $\mathrm{V} 1+\mathrm{NP} 1+\mathrm{V} 2+\mathrm{NP} 2^{23}$, i.e. $\mathrm{VP} 2$ functions as the complement of VP1, in which V1 only governs NP1, and V2 merely governs NP2. In the three types, V2 or VP2 functions as VP1's complement, representing result, purpose, or state of affairs. In this case, V2 or VP2, which functions as the complement of V1 or VP1,

${ }^{23}$ We do not take into consideration whether word order is SVO or SOV. In fact, we take only deep syntactic structure into account. In other words, this type includes NP+V1+NP+V2. 
is in a subordinate position, which can solve the problem that the asymmetrical c-command relationship between V1 and V2 is hard to determine. Even though V2 moves leftward to the same major predicate position as V1, V1 is not only prior to V2 linearly and sequentially but also higher than V2 in terms of syntactic hierarchy. Therefore, V1 still governs V2, and V2 still functions as V1's complement (cf. YANG 2009). ${ }^{24}$

\section{LEFT PERIPHERAL DELETION, OBJECT GAPPING, AND GENERATION OF SVCS}

An SVC is composed of two verbal phrases. They follow each other without an overt syntactic marking of the semantic relation between the described events. Thus we argue that an SVC is generated via combination of two clauses. The conjunction functioning as the connecting device between the two clauses is deleted, and the left peripheral is also deleted (i.e. LPD), which gives rise to an SVC, as illustrated in (49).

wo zhong cai

Chinese

1SG plant vegetable

'I plant vegetables.'

wo mai cai

1SG sell vegetable

'I sell vegetables.'

1SG plant vegetable sell

'I plant vegetables and sell them.'

As (49) shows, V1 is the major predicate, which bears the syntactic features and carries semantic weight. V2 is the secondary predicate, which bears no syntactic features and carries no semantic weight, because V2 has grammaticalized. In other words, VP2 is subordinate to VP1 and functions as the argument of VP1 (YANG 2009). The derivation can be shown as (50).

$$
\text { [VP1 VP1 VP2] }
$$

It follows that an SVC should be regarded as an IP headed by VP1. Rather, IP is the maximal projection of VP1. IP entails VP1 and VP2, between which there is no coordinate relation. Instead, there is subordinate relation between VP1 and VP2. VP1 c-commands VP2, and VP1 and VP2 share the same subject, which is situated in a high c-command position. It is noteworthy that an SVC should not be seen as a structure containing two IPs, because it has only one subject which dominates both VP1 and VP2. In fact, an SVC is

${ }^{24} \mathrm{We}$ argue that a bi-clausal analysis is not applicable to [V1 V2] in terms of SVCs. As mentioned above, V1, bearing syntactic features and carrying semantic weight, asymmetrically c-commands V2. V1 serves the function of the predicate, whereas V2 serves as the function of the complement. There is no coordination between V1 and V2, and hence [V1 V2] should not be analyzed as a bi-clause. 
composed of two VPs. The verb moves across the board (ATB) ${ }^{25}$ and adjoins to I, and the subject of VP1 and VP2 raises to [Spec IP], as shown in (51).

$$
\left.{ }_{I P} \operatorname{Subj}_{\mathrm{i}}\left[{ }_{\mathrm{r}} \mathrm{I}-\mathrm{V} 1_{\mathrm{j}}\left[_{\mathrm{VP} 1} \mathrm{t}_{\mathrm{i}}\left[_{\mathrm{V}} \mathrm{t}_{\mathrm{j}} \mathrm{O} 1\right]\left[_{\mathrm{VP} 2} \mathrm{t}_{\mathrm{i}}[\mathrm{V}, \mathrm{V} 2 \mathrm{O} 2]\right]\right]\right]\right]
$$

As (51) shows, V1 moves and merges with I, and V2 remains in situ. The advantages of this analysis are as follows: 1) an SVC is not a coordinate construction or adjunct construction but a subordinate construction; 2) V1 and V2 in an SVC project VP1 and VP2, which are within the same IP, as a consequence of which they share the same subject and its constituents, including tense, modal verbs, negative operators, and adverb modifiers. Obviously the analysis gives a reasonable account of the scope and variable binding of SVCs and hence overcomes the shortcoming of the conventional IP explanation of SVCs. Furthermore, it can account for other SVC phenomena, for example, V1 and V2 share the same subject but they do not share the same object. Subject sharing is a striking characteristic of SVCs and hence it is an obligatory condition of SVCs. In contrast, object sharing is not an obligatory feature of SVCs. Object sharing depends on the governing capability and scope of V1 and V2 as well as the occurrence of the object. However, VP1 dominates VP2, which is in a subordinate status. VP1 is in a governing status because V1, as the major predicate, bears tense/aspect markers and carries semantic weight. VP2 is in a subordinate status because V2 is the subordinate predicate or secondary predicate, which bears no tense/aspect markers and carries no semantic weight (YANG 2009). The analysis also makes the correct prediction that VP2 cannot be modified by S-adverbs and VP adverbs. It follows that if VP2 is an IP, SVCs are ungrammatical.

Thus, LPD is the prerequisite to the generation of SVCs via combination of two clauses. Since an SVC has only one IP, headed by VP1, V1 can bear tense/aspect markers (e.g. guo and $l e$ in Chinese) while V2 cannot. In other words, only one verb, i.e. V1, can bear tense/ aspect markers and function as the major predicate.

Zhangsan maiguo yige baozi chi

Zhangsan buy-PST one-CLASS steamed-stuffed-bun eat

'Zhangsan bought a steamed stuffed bun and ate it.'

$$
\text { *Zhangsan mai yige baozi chiguo }
$$

Zhangsan buy one-CLASS steamed-stuffed-bun eat-PST

Zhangsan bale yige luobo mai

Zhangsan pull-PST one-CLASS turnip sell

'Zhangsan pulled a turnip and sold it.'

*Zhangsan ba yige luobo maiguo

Zhangsan pull one-CLASS turnip sell-PST

\footnotetext{
${ }^{25}$ In general one cannot extract a single conjunct, though extraction from the conjuncts in an ATB fashion is permissible (Ross 1967; JACKENDOFF 1977; Williams 1978; GAZDAR et al. 1982; SAG et al. 1985; Goodall 1987; MunN 1993). AN (2006) argues that ATB constructions are derived by applying deletion in PF to a full sentential coordinate structure. Coordinate deletion is sensitive to the periphery. It implies that the element deleted should appear in the peripheral position or edge of the relevant portion of the structure. Furthermore, if an edge element is deleted, then the next element adjacent to the deletion site is considered to be peripheral and is subject to further deletion (up to other constraints such as identity).
} 
As (52)-(53) show, VP2 does not qualify as IP. If we compare coordinate constructions, pivotal constructions and SVCs, we will find that they are all generated on the basis of LPD but there are differences between them, as shown in (54)-(55).

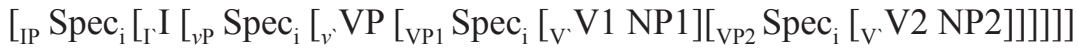

$$
\begin{aligned}
& {\left[{ }_{\mathrm{IP1} 1} \operatorname{Spec}_{\mathrm{i}}\left[\mathrm{I}_{\mathrm{I}} \mathrm{I}_{\mathrm{VP1}} \operatorname{Spec}_{\mathrm{i}}\left[{ }_{\mathrm{V}} \mathrm{V} 1 \mathrm{NP} 1\right]\left[_{\mathrm{IP} 2} \operatorname{Spec}_{\mathrm{j}}\left[_{\mathrm{r}} \mathrm{I}\left[_{\mathrm{VP} 2} \operatorname{Spec}_{\mathrm{j}}\left[{ }_{\mathrm{V}} \cdot \mathrm{V} 2 \mathrm{NP} 2\right]\right]\right]\right]\right]\right]} \\
& {\left[{ } _ { I P } \operatorname { S p e c } _ { \mathrm { i } } \left[_ { \mathrm { r } } \mathrm { I } { } _ { \text { IP1 } } \operatorname { S p e c } _ { \mathrm { i } } \left[_ { \mathrm { T } } \mathrm { I } \left[_{\mathrm{VP} 1} \operatorname{Spec}_{\mathrm{i}}\left[_{\mathrm{V}} \mathrm{V} 1 \mathrm{NP} 1\right]\right.\right.\right.\right.} \\
& \left.\left.\left.\left.\left[{ }_{\mathrm{IP} 2} \mathrm{Spec}_{\mathrm{i}}\left[{ }_{\mathrm{r}} \mathrm{I}\left[{ }_{\mathrm{VP} 2} \mathrm{Spec}_{\mathrm{i}}\left[{ }_{\mathrm{V}} \mathrm{V} 2 \mathrm{NP} 2\right]\right]\right]\right]\right]\right]\right]\right] \\
& \left.\left[\operatorname{IPpec}_{\mathrm{i}}\left[{ }_{\mathrm{I}} \mathrm{I}{ }_{\nu \mathrm{PP}} \operatorname{Spec}_{\mathrm{i}}\left[{ }_{v} \mathrm{~V} 1\left[_{\mathrm{VP} 1} \operatorname{Spec}_{\mathrm{j}}\left[{ }_{\mathrm{V}} \operatorname{pro}_{\mathrm{j}}\left[{ }_{\mathrm{VP} 2} \mathrm{~V} 2 \mathrm{NP}\right]\right]\right]\right]\right]\right]\right]
\end{aligned}
$$

The construction in (54) is an SVC, in which VP1 and VP2 share the same subject but do not necessarily share the object. The constructions in (55) are coordinate constructions. In (55a), IP1 and IP2 do not share the same subject, whereas in (55b) IP1 and IP2 share the same subject. The construction in (56) is a pivotal construction, in which the internal argument of VP1 is the external argument of VP2, and it occurs as pro. VP1's specifier is of dual property, i.e. it functions as V1's object and V2's subject. Thus the LPD between the two clauses may give rise to two types of constructions. If VP1 and VP2 share the same subject, and V1 and V2 share the internal argument, an SVC may be generated. If VP1 and VP2 do not share the same subject, and V1 and V2 share the same NP, which functions as the internal argument of V1 and the external argument of V2, a pivotal construction may be generated.

A subject sharing coordinate construction may generate an SVC if the conjunction and the left peripheral are deleted. VP2, whose subject occurs as pro, is embedded in VP1. Hence VP2 is subordinate to VP1 and c-commanded by VP1. In this process, VP2's subject and VP1's subject merge into VP's subject, which moves to [Spec IP]. VP2's subject and VP1's object in a subject sharing coordinate construction incorporate as an overt NP, which has two functions: VP1's object and VP2's subject. As a result, a pivotal construction is generated. A coordinate construction has two IPs, which both bear tense/aspect markers. If VP1 and VP2 do not share the same subject, there are two different subjects. In contrast, if they share the same subject, only VP1's subject can occur overtly, but VP2's subject has to occur as pro, which co-refers with the overt subject and is controlled by it. An SVC has an IP, which contains a $v \mathrm{P}$ and a VP. $v \mathrm{P}$ 's specifier moves to occupy [Spec IP]. The subject governs $v \mathrm{P}$ and VP. VP is c-commanded by $v \mathrm{P}$ and functions as its internal argument. A pivotal construction has a VO structure, i.e.V1O1, and a subject-predicate structure, i.e. S2V2. S2 is equal to O1. V1's object and V2's subject incorporate as an overt object NP, which also functions as V2's subject. Thus a coordinate construction implicates an SVC and a pivotal construction.

LPD causes two combined constructions to generate an SVC and the shared object O2 to be deleted. However, such operations cannot trigger V2 to promote. In fact, the object gapping of SVCs is the root cause of V-I movement. If object gapping is present in SVCs in a language, $\mathrm{V}$ can raise to I. Conversely, if object gapping is not present in SVCs in a language, V cannot raise to I. Specifically, object gapping is not present in Chinese SVCs, whereas it is present in SVCs in Tibeto-Burman languages. Hence the former does not undergo overt V-I movement while the latter undergoes overt V-I movement. Take the Chinese SVC wo zhongguo cai mai for example. Its generation is shown as (57). 
$(57 \mathrm{a})$

$$
\begin{aligned}
& \text { wo zhongguo cai + wo maiguo cai } \\
& \begin{array}{l}
\rightarrow \text { SG plant vegetable } 1 \text { SG sell vegetable } \\
\rightarrow \text { wo zhongguo cai CONJ wo maiguo cai } \\
\rightarrow \text { wo zhongguo cai } € \text { wN wo maiguo cai } \\
\rightarrow \text { wo zhongguo cai wo maiguo cai } \\
\rightarrow \text { wo zhongguo cai maiguo cai } \\
\rightarrow \text { wo zhongguo cai mai eai } \\
\rightarrow \text { wo zhongguo cai mai }
\end{array}
\end{aligned}
$$

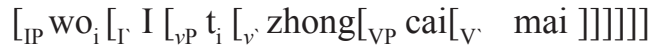

$$
\begin{aligned}
& \text { 1SG plant vegetable sell } \\
& \text { 'I plant vegetables and sell them.' }
\end{aligned}
$$

As (57a) shows, the combination of the two clauses wo zhongguo cai and wo maiguo cai gives rise to the sentence wo zhongguo cai CONJ wo maiguo cai. According to the definition of the SVC, there is no connective device between the VPs. Hence the conjunction must be deleted, which yields wo zhongguo cai €ӨN wo maiguo cai. The deletion of the conjunction results in the LPD of the second clause. According to the assumption that the verbs of the SVC share the same subject, the subject of the second clause has to occur covertly, viz. pro, which yields wo zhongguo cai pro maiguo cai. Since only one of the verbs can occur as the major predicate of the SVC and bear the tense/aspect marker guo, the tense/aspect marker guo of the second clause must be deleted. On the other hand, since the verbs in the two clauses share the same object, the object in the second clause must be deleted to avoid syntactic redundancy. As a consequence, wo zhongguo cai mai is generated. (57b) shows that object gapping is not present in SVCs in Chinese, V cannot be triggered to raise to I. It follows that Chinese SVCs undergo no object gapping but object deletion, i.e. co-referential O2 deletion. In contrast, Yi, Qiang, Kazhuo, Hani, and Lahu, which belong to the Tibeto-Burman family, undergo object gapping, and hence $\mathrm{V}$ moves to I overtly, as illustrated in (58).

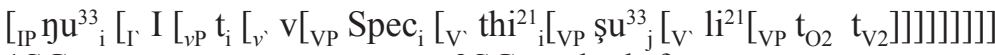

$$
\begin{aligned}
& \text { 1SG 3SG look-for go } \\
& \text { 'I'll go to look for him.' }
\end{aligned}
$$

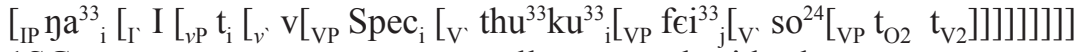

$$
\begin{aligned}
& 1 \mathrm{SG} \text { collar embroider learn }
\end{aligned}
$$

As (58) shows, $\mathrm{O} 1$ is null, and $\mathrm{O} 2$ moves to $\mathrm{O} 1$ in order to receive a theta-role. In order to assign $\mathrm{O} 2$ a theta-role, $\mathrm{V} 2$ moves to $v$ and merges with it, which gives rise to a combination $\mathrm{S}+\mathrm{O} 2+\mathrm{V} 2+\mathrm{V} 1$. If $\mathrm{O} 1$ is not null, $\mathrm{O} 2$ and $\mathrm{V} 2$ may not be triggered to move. Thus object gapping is the root cause of overt verb raising.

Object movement in SVCs is A-movement, which follows the Coordinate Structure Constraint (CSC) proposed by Ross (1970). Both A-movement and verb movement are characteristic of ATB (BoŠKoviĆ 1997). If O1 is null, or rather, O1 has the feature [-ACC], $\mathrm{O} 2$ and V2 will move to [NP $\left.\mathrm{V}^{`}\right]$ and [V VP] respectively, as illustrated in (59). 


$$
\begin{aligned}
& \mathrm{yu}^{33} \Phi[-\mathrm{ACC}] \mathrm{li}^{21} \mathrm{thi}^{21} \mathrm{su}^{33} \\
& 1 \mathrm{SG} \quad \text { go him search }
\end{aligned}
$$

$$
\rightarrow \mathrm{yu}^{33} \text { thi }^{21} \text { şu }^{33} \quad \mathrm{li}^{21}
$$

1SG him search go

$$
\begin{aligned}
& \mathrm{ya}^{33}[-\mathrm{ACC}] \mathrm{so}^{24} \text { thu }^{33} \mathrm{ku}^{33} \mathrm{fei}^{33} \\
& \text { 1SG learn collar embroider }
\end{aligned}
$$

According to CHOMSKY (1995), the structure of VP is [ $v \mathrm{P}[\mathrm{VP}]]$. The verb moves overtly to $v$, but it does not raise to the position I. The subject is base-generated in [Spec $v \mathrm{P}]$ and the object is base-generated in [Spec VP]. This analysis sees SVCs as $v \mathrm{P} / \mathrm{VP}$ instead of $\mathrm{VP} / \mathrm{VP}$. The verb moves across the board to $v$, and $v \mathrm{P}$ or VP is the internal structure of the whole syntax. In $v \mathrm{P}$ the constituent in the specifier position is the subject while in VP it is the object. SVCs in Tibeto-Burman languages undergo both object gapping and LPD. Furthermore, SVCs in all languages undergo object gapping and ATB movement, which result from LPD. VP2 functions as $v \mathrm{P}$ in terms of object gapping and functions as VP in terms of ATB movement. According to the economy principle of language processing, VP/VP is a completely symmetrical coordinate structure. But $v \mathrm{P} / \mathrm{VP}$ is different. It is noteworthy that $v \mathrm{P} / \mathrm{VP}$ is not a licensing condition. Japanese, Korean, Yi, Qiang, Hani, Kazhuo, and Lahu are all SOV languages. Why is only the word order S+O1+V1+V2 allowed in Japanese and Korean SVCs? Why are both the word order S+V1+O1+V2 and S+O2+V2+V1 allowed in Yi, Qiang, Hani, Kazhuo, and Lahu SVCs? We argue that this is due to object gapping, or rather, $\mathrm{O} 1$ gapping. It can be inferred that $\mathrm{O} 1$ gapping is the prerequisite to the generation of $\mathrm{S}+\mathrm{O} 2+\mathrm{V} 2+\mathrm{V} 1$. According to YANG (2009), in SVO-type SVCs, the aspect marker is generated in $\left[v v^{\prime}\right]$. V1 moves from [V $\left.\mathrm{V}^{\prime}\right]$ to $\left[v v^{\prime}\right]$ and merges with the aspect marker. The subject is generated within $v \mathrm{P}$. It moves to [Spec IP] to satisfy the requirement of the EPP feature. $\mathrm{O} 1$ and $\mathrm{O} 2$ are in [NP VP] and [NP V'] respectively, as shown in (60a). In SOV-type SVCs, V1 remains in situ and V2 is in [V V'], as shown in (60b). The subject is generated within $\nu \mathrm{P}$. It moves to [Spec IP] to satisfy requirement of the EPP feature. $\mathrm{O} 1$ and $\mathrm{O} 2$ are in outer [NP $\mathrm{V}^{\prime}$ ] and inner [NP $\mathrm{V}^{\prime}$ ] respectively. If $\mathrm{O} 1$ is null, $\mathrm{O} 2$ and $\mathrm{V} 2$ move to outer [NP $\mathrm{V}^{\prime}$ ] and [V VP] respectively, as shown in (60c).

$$
\begin{aligned}
& {\left[{ }_{I P} \operatorname{Spec}_{\mathrm{i}}\left[\mathrm{I}_{\mathrm{I}} \mathrm{I}_{{ }_{v \mathrm{P}}} \mathrm{t}_{\mathrm{i}}\left[{ }_{v}, v-\mathrm{V}\left[\mathrm{VP}_{\mathrm{P}} \operatorname{Spec}_{\mathrm{i}}\left[\left[_{\mathrm{V}} \mathrm{t}_{\mathrm{V} 1}\left[{ }_{\mathrm{VP}} \mathrm{NP}\left[{ }_{\mathrm{V}} \mathrm{V} N \mathrm{NP}\right]\right]\right]\right]\right]\right]\right]\right.} \\
& \begin{array}{lllll}
\mathrm{S} & \mathrm{V} 1 & \mathrm{O} 1 & \mathrm{~V} 2 & \mathrm{O} 2
\end{array}
\end{aligned}
$$

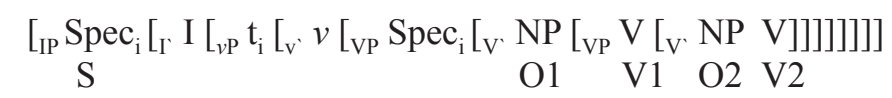

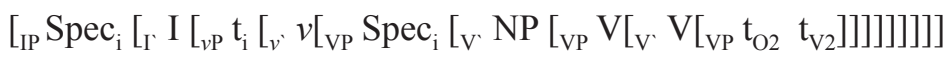

$$
\begin{aligned}
& \begin{array}{lll}
\mathrm{S} & \mathrm{O} 2 & \mathrm{~V} 2 \\
\mathrm{~V} 1
\end{array}
\end{aligned}
$$

As (60) shows, in SVO-type SVCs V1 moves to $v$ and merges with it, whereas in SOVtype SVCs V1 remains in situ. Thus in SVO-type SVCs, even if O1 is null, O2 and V2 cannot be triggered to move to the position preceding V1, as a consequence of which the word order SO2V2V1 cannot be generated. In SOV-type SVCs, if O1 is null, or if O1 bears the feature [-ACC], $\mathrm{O} 2$ and $\mathrm{V} 2$ raise to the positions [NP $\left.\mathrm{V}^{\prime}\right]$ and [V VP] respectively, as shown in (61). In other words, the generation of the word order SO2V2V1 depends on whether O1 has the feature $[-\mathrm{ACC}]$ or not.

$$
\mathrm{S} \mathrm{O} 2_{\mathrm{i}} \mathrm{V} 2_{\mathrm{j}} \mathrm{V} 1 \mathrm{t}_{\mathrm{i}} \mathrm{t}_{\mathrm{j}}
$$


(62a)

Chelswu-ka chayksang-ul [+ACC] twutulki-e pwusi-ess-ta

Korean

Chelswu-NOM table-ACC beat break-PST-DEC

$\rightarrow{ }^{*}$ Chelswu-ka chayksang-ul pwusi-ess-ta twutulki-e Chelswu-NOM table-ACC break-PST-DEC beat

(62b)

John Mary-ra [+ACC] pruk-an Bill plap-an

Miskito

John Mary-ACC beat Bill run-PST

$\rightarrow$ * John Mary-ra Bill plap-an pruk-an

John Mary-ACC Bill run-PST beat

$(62 c)$

(63a)

Áràú ingo $[+\mathrm{ACC}]$ dérì pite-mí

3SG net knit set-PST

$\rightarrow$ *Áràú ingo pite-mí dérì

3SG net set-PST knit

$$
\begin{aligned}
& \text { the: } \Phi[-\mathrm{ACC}] \text { topu fa xsə guə } \\
& \text { 3SG like clothes new wear } \\
& \rightarrow \text { the: fa } \quad \text { xsə guə topu } \\
& \text { 3SG clothes new wear like }
\end{aligned}
$$$$
\mathrm{ya}^{55} \Phi[-\mathrm{ACC}] \mathrm{li}^{33} \mathrm{xo}^{31} \mathrm{t}_{6 \mathrm{a}^{31}}
$$$$
\text { 1SG go rice cook }
$$

Hani

$\rightarrow \mathrm{ya}^{55} \quad \mathrm{xo}^{31} \mathrm{t} \mathrm{a}^{31} \quad \mathrm{li}^{33}$

$1 \mathrm{SG}$ rice cook go

$$
\begin{aligned}
& \mathrm{ya}^{31} \Phi[-\mathrm{ACC}] \mathrm{ga}^{53} \mathrm{ma}^{21} \mathrm{za}^{53} \mathrm{te}^{31} \\
& \text { 1SG want soldier be } \\
& \rightarrow \mathrm{ya}^{31} \mathrm{ma}^{21} \mathrm{za}^{53} \mathrm{te}^{31} \mathrm{ga}^{53} \\
& \text { 1SG soldier be want }
\end{aligned}
$$

As (62) shows, in SVCs in Korean, Miskito, and Ijo, O1 is not null, and hence neither $\mathrm{O} 2$ nor V2 can move into the position. As a consequence, the word order $\mathrm{S}+\mathrm{O} 2+\mathrm{V} 2+\mathrm{V} 1$ cannot be generated. In contrast, in SVCs in Yi, Qiang, Hani, and Lahu, O1 is null, and hence $\mathrm{O} 2$ can move into the position to give rise to $\mathrm{S}+\mathrm{O} 2+\mathrm{V} 2+\mathrm{V} 1$, as shown in (63).

According to MuYsken \& Veenstra (1995) and YAng (2009), the verbs in SVCs have the following features: 1) they share the same subject; 2) they have at most one direct object ${ }^{26}$; 3 ) tense/aspect markers adjoin to V1 or V2;4) there is only one negative particle; 5) there is no coordinate or subordinate conjunction; 6) there is no pause; 7) the higher constituent in the syntactic hierarchy governs the lower constituent in the syntactic hierarchy. $\mathrm{O} 1$ is more prominent than $\mathrm{O} 2$. Thus $\mathrm{O} 1$ can bind $\mathrm{O} 2$ asymmetrically. In syntax VP1's projection is higher than that of VP2, and VP2 is embedded in VP1, as shown in (65a). If V1 is a transitive verb, SVCs are similar to ditransitive constructions, as shown in (64b) (cf. DeCHAINE 1988).

$$
\begin{aligned}
& {[\mathrm{IP}[\mathrm{I}[\mathrm{VP} 1[\mathrm{VP} 1][\mathrm{VP} 2]]]]} \\
& {[\mathrm{IP}[\mathrm{I}[\mathrm{VP} 1[\mathrm{~V} 1][\mathrm{VP} 2]]]]}
\end{aligned}
$$

${ }^{26}$ Only V1 takes an overtly realized direct object. The unrealized object of V2 is understood to be co-referential with O1 (cf. MüLLER \& LiPENKova 2009). 
Li \& ThOmpson (1981) analyzes VP1 as an adverbial phrase, which adjoins to and modifies VP2, as shown in (65).

$$
\left[{ }_{I P} \operatorname{Subj}_{\mathrm{i}}\left[{ }_{\mathrm{VP}}\left[_{\text {Adjunct clause }} \operatorname{pro}_{\mathrm{i}} \mathrm{VP} 1\right] \mathrm{VP} 2\right]\right]
$$

In this case, the Chinese SVC ta gui xialai qiu wo has the following structure:

$$
\begin{aligned}
& \text { [IP } \left.\operatorname{ta}_{\mathrm{i}}\left[{ }_{\mathrm{VP}}\left[\text { Adjunct clause } \text { pro }_{\mathrm{i}} \text { gui xialai }\right] q \text { qu wo }\right]\right] \\
& 3 \mathrm{SG} \quad \text { kneel down beg } 1 \mathrm{SG} \\
& \text { 'He begged me kneeling down.' }
\end{aligned}
$$

PAUL (2005) argues that SVCs can be analyzed not only as an adjunct structure, but also as a purposive clause structure, as shown in (67).

$$
\left[{ } _ { I P } \operatorname { S u b j } _ { { } _ { i } } [ { } _ { V P } V P 1 ] \left[\text { Purposive clause }_{\text {pro }}\right.\right. \text { VP2]] }
$$

According to (67), the Chinese SVC ta da dianhua jiaoche has two possible analyses, as shown in (68).

$$
\begin{aligned}
& \text { [IP } \left.\operatorname{ta}_{\mathrm{i}}\left[\mathrm{VP}_{\mathrm{VP}} \text { Adjunct clause }_{\text {pro }_{\mathrm{i}}} \text { da dianhua }\right] \text { jiao che }\right] \text { ] } \\
& 3 \mathrm{SG} \\
& \text { beat phone call car }
\end{aligned}
$$

(adjunct)

'He phoned to call a taxi.'

$$
\begin{aligned}
& \text { [IP } \left.\text { ta }_{\mathrm{i}}[\mathrm{VP} \text { da dianhua }]\left[\text { Purposive clause } \text { pro }_{\mathrm{i}} \text { jiao che }\right]\right] \\
& \text { 3SG beat phone call car } \\
& \text { 'He phoned to call a taxi.' }
\end{aligned}
$$

Hence the internal structure of SVCs can be analyzed as follows:

$$
\begin{array}{ll}
\text { VP1 } & \text { VP2 } \\
\text { adjunct } & \text { major predicate } \\
\text { major predicate } & \text { purposive clause } \\
\text { (VP2's covert subject pro is controlled by the matrix subject) }
\end{array}
$$

Li \& THOMPSON (1981) point out that an SVC may be understood to be related in one or more of the following four ways: 1) consecutive; 2) purpose; 3) alternating; 4) circumstance. VP1 modifies VP2 and they express a single event instead of two separate events. Collins (1997: 46) argues that V1 and V2 share the same internal argument instead of the same object.

Wo da fufu du

Ewe

3PL cook fufu eat

'They cooked fufu and ate it.'

(70b)

$$
\begin{aligned}
& \text { Me nya devi-e dzo } \\
& 1 \mathrm{SG} \text { chase child leave } \\
& \text { 'I chased the child away.' }
\end{aligned}
$$

Ewe

In (70a) fufu is the common object of V1 $d a$ and V2 $d u$. In (70b) devi is the object of V1 nya and the unique argument of V2 $d z o$. According to (54), the internal structure of (70a) is as follows:

$$
\begin{aligned}
& {\left[{ }_{v \mathrm{P}} \mathrm{Wo}\left[{ }_{v^{\prime}} \operatorname{cook}\left[{ }_{\mathrm{VP} 1} \text { fufu }_{\mathrm{i}}\left[\mathrm{v}_{\mathrm{V} 1} \cdot \mathrm{t}_{\mathrm{cook}}\left[\mathrm{VP}_{\mathrm{VP}} \operatorname{pro}_{\mathrm{i}}\left[\mathrm{v}_{\mathrm{V} 2}, \mathrm{du}\right]\right]\right]\right]\right]\right]} \\
& \text { 3PL cook fufu eat }
\end{aligned}
$$


In (71) V1 takes VP2 as its complement and the covert internal argument of V2 is coreferential with that of V1. More precisely, the object of V1 controls the empty category in [Spec VP2]. In other words, VP2 is analyzed as a kind of secondary predication. V raises to $v$ and merges with it. Since V1 and V2 share the same argument, V2 cannot be followed by an overt NP. If V2 is followed by an overt NP, the construction is ungrammatical, as illustrated in (72).

$$
\begin{aligned}
& \text { Wo-a da fufu du- }\left(*_{i}\right) \\
& \text { 3PL-FUT cook fufu eat } 3 \mathrm{SG} \\
& \text { 'They will cook fufu and eat it.' }
\end{aligned}
$$

Ewe

Whereas in the SVC in Ewe the future is marked only on V1, in a coordinate structure it must appear in front of each verb (CoLLINs 1997).

$$
\begin{aligned}
& \text { Me fo kadegbe gba } \\
& 1 \mathrm{SG} \text { hit lamp break } \\
& \text { 'I hit the lamp and broke it.' }
\end{aligned}
$$

$$
\begin{aligned}
& \text { Me a fo kadegbe gba } \\
& \text { 1SG FUT hit lamp break } \\
& \text { 'I will hit the lamp and break it.' }
\end{aligned}
$$

$$
\begin{array}{llllll}
\text { Me a fo kadegbe } & *(a) \text { gba } & \text { (yeme) } & \text { tsimini } \\
\text { 1SG FUT hit lamp FUT break } & \text { 3SG-GEN glass } \\
\text { 'I will hit the lamp and break its glass.' }
\end{array}
$$

The constructions in (73a) and (73b) are SVCs but the construction in (73c) is a coordinate construction. In (73c) the future is marked on V1 and V2, which do not share the same argument. This testifies our hypothesis that V1 can bear an aspect marker and its maximal projection is $v \mathrm{P}$, whereas $\mathrm{V} 2$ cannot bear any aspect marker and its maximal projection is VP. Hence V1 and V2 have different syntactic status.

According to BAKER \& STEWART (2002), there are three types of SVCs, viz. object sharing SVCs, resultative SVCs, and purposive SVCs. In SVCs in Yorùbá, mood/tense is marked on the verb. Likewise, the Misumalpan languages Miskito and Sumu display a rather rich inflectional morphology: the verb is not only marked for tense and person, but also for proximate (same subject) vs. obviative (different subject) (cf. STAHLKe 1970; Hale 1991). An SVC can spell out the $v$-V combination as one single lexical element, whereas a non-SVC cannot. ${ }^{27}$ In the combination V1NPV2, if V1 does not assign NP a theta-role, the construction is not an SVC but a pivotal construction (DEN DikKen \& Sybesma 1998).

${ }^{27}$ This statement is supported by the following data.

(i) a. Mama jin cheng mai dongxi. mother enter town buy thing 'Mother went to town and bought some things.'

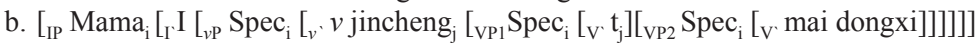

(ii) a. Zhangsan changge tiaowu. coordinative construction Zhangsan sing dance 'Zhangsan sings and dances.'

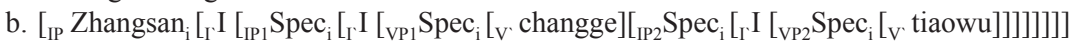

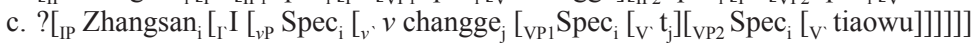




$$
\begin{aligned}
& {\left[_{V P}[\text { gan }]\left[{ }_{S C}\left[{ }_{N P} \text { Zhangsan }\right]\left[{ }_{X} \text { zou }\right]\right]\right]} \\
& \text { expel Zhangsan leave } \\
& \text { 'chase Zhangsan away' }
\end{aligned}
$$

Chinese

${ }_{{ }_{v P}}\left[{ }_{v}\right.$, ba $]\left[{ }_{F P} Z_{\text {hangsan }}\left[{ }_{F}, F_{\text {ASP }}\left[{ }_{V P} \operatorname{gan}\left[{ }_{S C}\left[{ }_{N P} t_{i}\right]\left[{ }_{X}\right.\right.\right.\right.\right.$ zou $\left.\left.\left.\left.\left.]\right]\right]\right]\right]\right]$

Chinese

$$
\text { BA Zhangsan expel leave }
$$

'chase Zhangsan away'

The "dummy" element $b a$ is inserted into $v$ and the NP raises to [Spec FP] between $v$ and $\mathrm{V}$. The verb does not raise to $v$, and hence $v$ is therefore lexicalized by an independent morpheme. The positioning of the object depends on the nature of the object NP involved ([ \pm definite $]$ etc.), as illustrated in (75).

$$
\begin{aligned}
& \text { ta }\left[_ { V P } \text { song-le } \left[_{V P 1}\right.\right. \text { yige } \\
& \text { xiangzi } t_{\text {song }[\text { VP2 }} \text { pro lai]]] }
\end{aligned}
$$

Chinese

'He sent a suitcase over here.'

ta $\left[_{\mathrm{VP}}\right.$ song-le $\left[_{\mathrm{VP} 1}\right.$ yige

3SG send-PST one-CLASS

'He sent a suitcase over here.'

$$
\left.\left.\operatorname{xiangzi}_{\mathrm{i}}\left[\mathrm{V}_{\mathrm{V} 1} \cdot \mathrm{t}_{\mathrm{song}}\left[\mathrm{VP2} \text { pro }_{\mathrm{i}} \text { lai }\right]\right]\right]\right]
$$

Chinese suitcase come

$$
\operatorname{ta}\left[_ { v \mathrm { P } } \mathrm { V } \text { songlai-le } \left[_{\mathrm{VP} 1}\right.\right. \text { yige }
$$

3SG send-come-PST one-CLASS

$$
\text { xiangzi } \left.\left._{i}\left[\mathrm{v} 1_{1} \cdot \mathrm{t}_{\mathrm{song}}\left[\mathrm{vP} 2_{2} \text { pro }_{\mathrm{i}} \mathrm{t}_{\mathrm{lai}}\right]\right]\right]\right]
$$

Chinese

'He sent a suitcase over here.' suitcase

Due to LPD, IP2 is demoted to be VP2, as a consequence of which it loses its tense/ aspect marker and lies in a secondary predicate position. The semantic weight transfers to VP1, within which V1 moves to the major predicate position. VP1's subject moves to [Spec IP] and c-commands VP1 and VP2. In the meanwhile, LPD causes the overt NP in front of VP2 to function as the internal argument of VP2. The external argument, occurring as pro, is controlled by NP1, the specifier of IP. VP1's subject and VP2's subject are generated inside themselves and then move to their specifier positions respectively. Since VP1 c-commands VP2 and VP1's subject moves to [Spec IP] overtly, VP2's subject occurs as pro controlled by VP1. If VP2's subject occurs overtly, the construction is ungrammatical whether VP2's subject co-refers with IP's specifier or not. A simplex sentence can contain only one subject. If VP2's subject and IP's specifier do not co-refer, the overt occurrence of VP2's subject violates the constraint. If VP2's subject and IP's specifier co-refer, VP2's subject cannot occur overtly. In other words, VP2 does not qualify as an independent IP or SC (small clause). The overt NP in front of it can only function as an internal argument instead of an external argument. In this way we can provide a reasonable account of generation of the constructions SV1O1O2V2 and SV1OV2. The overt NP in front of VP2 is the shared object of V1 and V2. If V2 is transitive, it governs NP directly. If it is intransitive, it is causative and governs NP indirectly. NP functions as the shared internal argument of V1 and V2 (YANG 2009).

(iii) a. Zhangsan changge Lisi tiaowu. coordinative construction

Zhangsan sing Lisi dance

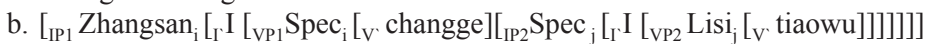

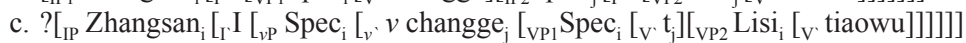

As (i)-(iii) show, the underlying structure of SVCs is different from that of coordinative constructions. 
(76a)

$\mathrm{wo}_{\mathrm{i}}$ zhuazhu shuzhi pro $_{i}$ pashangqu

Chinese

1SG grasp branch climb-up

'I grasped the branch and climbed it.'

*wo zhuazhu shuzhi wo pashangqu

Chinese

1SG grasp branch 1SG climb-up

As (76a) shows, VP2's subject occurs as pro, and V1 and V2 share the object shuzhi. As (76b) shows, VP2's subject occurs as an overt NP, and V1 and V2 share the object shuzhi, as a consequence of which the construction is ungrammatical. It follows that external argument sharing is the obligatory requirement for the existence of SVCs, whereas internal argument sharing is the optional requirement for the existence of SVCs.

BAKER (1989) argues that if V1 of an SVC takes an object, V2 must theta-mark this object as well. An argument can receive more than one theta-role as long as all its theta-roles are assigned to the same structural position. Therefore, one crucial element in SVCs is that V2 must be able to assign a theta-role to an NP, and that the NP is in the object position for $\mathrm{V} 1$ and V2. Thus V2 can be followed by no object because it cannot assign two internal theta-roles. The relation between V1 and V2 is determined by the temporal order of the two events they represent. In other words, verbs in SVCs follow the Temporal Iconicity (cf. WANG 2007; YANG 2009). ChANG (1990) proposes two constraints on SVCs, viz. PTS (Principle of Temporal Sequence) ${ }^{28}$ and shared reference.

$$
\begin{aligned}
& \text { wo zhong cai mai } \\
& \text { 1SG plant vegetable sell }
\end{aligned}
$$

$$
\text { wo meitian zhong cai mai }
$$

1 SG every-day plant vegetable sell

'I plant vegetables and sell them every day.'

$$
\begin{array}{lll}
* \text { wo zhong cai meitian mai } \\
\text { 1SG plant vegetable every-day sell }
\end{array}
$$

Adverbial modifiers can occur in front of VP1, whereas no adverbial modifier can appear in front of VP2. Hence (77c) is ungrammatical. The generation of (77a) is shown as follows:

$$
\begin{aligned}
& {\left[\begin{array}{l}
\left.{ }_{\mathrm{VP}} \text { mai cai }\right] \\
\rightarrow\left[{ }_{\mathrm{TP}}[\text { mai cai }]\right] \\
\text { sell vegetable }
\end{array}\right.} \\
& \rightarrow\left[{ }_{\mathrm{TP}} \mathrm{WO}[\mathrm{VP} \text { mai cai }]\right] \\
& \quad 1 \mathrm{SG} \text { sell vegetable } \\
& \rightarrow\left[{ }_{\mathrm{V}} \text { zhong }\left[\mathrm{TP}_{\mathrm{TP}} \text { wo }[\mathrm{VP} \text { mai cai }]\right]\right] \\
& \quad \text { plant } 1 \mathrm{SG} \text { sell vegetable }
\end{aligned}
$$

\footnotetext{
${ }^{28}$ The interpretation that an event depends on the event preceding it is based on our understanding of the real world, in which events unfold along a time dimension (CHANG 1990). Language comprehenders exploit the linearity of discourse when building their representations of temporal aspects of the situation (CHAFE 1979; COMRIE 1985; DowTy 1986; Givón 1992; Hopper 1979). By default, readers assume that the order of verbs corresponds to the chronological order of the actions or events in the situation referred to, so that successive verbs describe successive actions or events (DE VEGA et al. 2004).
} 


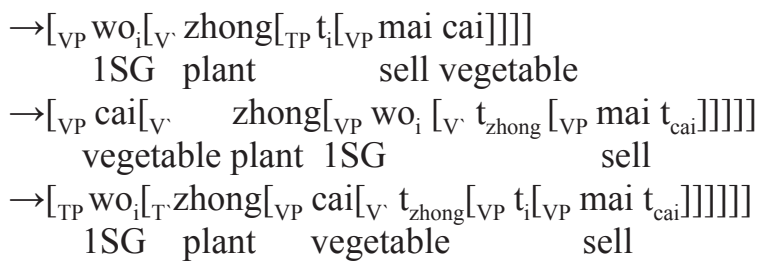

(79a) wo dao-le sanbei shui he-le $\Phi$

Chinese

1SG pour-PST three-CLASS water drink-PST

'I poured three glasses of water to drink.'

(79b) wo dao-le sanbei shui he-le yibei $e$ Chinese

1SG pour-PST three-CLASS water drink-PST one-CLASS REF

'I poured three glasses of water and drank one of them.'

As (79) shows, V1 and V2 in the SVC share NP shui, whereas V1 and V2 in the nonSVC do not share the whole NP but only the head noun shui, excluding the classifier bei, for bei carries the referential meaning. CHANG (1990) argues that the verbs of an SVC hold a temporal dependency relation and share a common NP. The shared common NP denotes a shared reference. Thus SVCs undergo the deletion of a redundant NP2, which follows $\mathrm{V} 2$, for the sake of economy. The thematic structure (PTS) is mapped into the functional structure (shared reference), which is different from BAKER's (1989) approach that the constituent structure is mapped from the constituent structure to the thematic structure: doubleheads are designed to meet the needs of theories rather than to describe and explain language in real use (cf. WANG 2007). V2 modifies V1 and functions as V1's purpose. V1 is higher than V2 in syntactic hierarchy. The difference between V1 and V2 lies in their linear order and related semantic relationship (cf. YANG 2009). Furthermore, the relationship of the two verbs is subordinate. The two events indicated by VPs are sequential and serial.

$$
\begin{aligned}
& \text { wo zhong cai mai-le } \Phi \\
& 1 \text { SG plant vegetable sell-PST } \\
& \text { 'I planted vegetables and sold them.' } \\
& \text { wo mai shu kan-le } \Phi \\
& 1 \text { SG buy book read-PST } \\
& \text { 'I bought a book and read it.' }
\end{aligned}
$$

Chinese

Chinese

Quantifier Floating and VP-Internal Subject Hypothesis can prove that VP2 in the SVC is not IP2. A quantifier is base-generated as part of the subject DP. After the subject raises from [Spec VP] to [Spec IP], the quantifier can remain in situ. In the SVC, however, IP2's subject cannot remain in situ if it contains the subject (cf. SPORTICHE 1988; KoOPMAN \& SPORTICHE 1991; MCCLOSKEY 1997). NP in the QP (quantifier phrase) is constrained syntactically, i.e. the semantic property of the NP object must be licensed. O1 and $\mathrm{O} 2$ have the same semantic reference and value. O1's semantic reference property determines O2's semantic reference property. If the former is definite, the latter must be definite. On the contrary, if the former is indefinite, the latter must be indefinite. It follows that $\mathrm{O} 2$ 's syntactic-semantic features must be licensed by $\mathrm{O} 1$. If the QP functioning as the internal argument of $\mathrm{V} 2$ fails to be licensed 
by syntax, the construction would be ungrammatical. $\mathrm{O} 1$ can be indefinite, but $\mathrm{O} 2$ must be definite. If $\mathrm{O} 2$ occurs as a full NP, the construction would be ungrammatical.

According to LI (2005), if there is coordination between two clauses, the predicate VP of the second clause can be deleted. Coordination, however, is a necessary condition.

$$
\begin{aligned}
& \text { John will be there; Bill will [be there], too. } \\
& \text { John will be there; Bill will [ ], too. }
\end{aligned}
$$

These are instances of phonological representation deletion. In this case, deletion is optional. Hence (81a) and (81b) are both grammatical. In (81b) the optional null constituent does not require an antecedent; deletion is applied without antecedents (cf. HANKAMER \& SAG 1976).

According to KAYNE (1994) and Nunes (1995), deletion is applied due to linearization. The form of the empty category in elliptical structures is base-generation of the null form. Only the constituent chosen by the head can occur in the null form. The null category in elliptical structures occurs for the purpose of satisfying the selection property of the head. The selection of the empty category is subject to the following constraints: 1) if the head takes the empty category (E) as its complement, E must project; 2) E can be generated in the null form (i.e. no lexical form) only when it is selected by the head. This shows that the empty constituent projects for the mere purpose of satisfying the selection constraint of the head. A transitive verb requires an object. If the verb is followed by no overt object, the object is null. In this way the selection constraint is satisfied. Only the selected constituent can project, viz. the missing constituent in VP can be the object of the transitive verb (Li 2005). When the verb is ditransitive, its subcategorzation feature requires its two objects to occur simultaneously. In this case the missing constituents are two objects.

The null object in Chinese does not occur overtly, viz. there is no lexical item to bear accusative Case. Like other languages with overt morphological Case markers, NP in Chinese is assigned Case. The assignment of Case is in conformity with Visibility Conditions and Theta Criterion (Travis 1984; KoOpMan 1984; Li 1985). The empty constituent occurs in the argument position (SAITo 1985). It needs to be licensed by the formal features of a specific head. In other words, it must be Case marked (cf. LoBECK 1995, 1999; Li 2005). In the case of Case assignment, Case must be realized by an overt constituent. In the case of non-Case assignment, an empty constituent cannot occur. If a verb takes a noun as its object, the object may be null. If a verb is transitive and its subcategorization features require that a noun function as its object, it must merge with e with the category feature $[+\mathrm{N}]$.

$$
\left[{ }_{\mathrm{VP}} \mathrm{Ve}_{\mathrm{DP}}\right. \text { ] }
$$

Deletion takes place in the chain which is formed due to movement. But head ellipsis does not take place because a head which selects a complement cannot be generated in the null form (Li 2005).

In terms of $\mathrm{S}+\mathrm{V} 1+\mathrm{V} 2$, V2 denotes purpose, its subject occurring as pro. V1's object can be definite or indefinite. On the contrary, V2's object must be definite, and its valuation depends upon V1's object. In this way, the operator-variable relation between the two objects is formed. In view of technology, V2's object is actually an empty operator, which moves to $[$ Spec CP] and leaves a variable in the object position.

$$
\mathrm{S}_{\mathrm{i}} \mathrm{V} 1 \mathrm{O} \text { pro }_{\mathrm{i}} \mathrm{V} 2 \text { variable }
$$


The variable must be licensed by the operator $\mathrm{O}$, and the variable and the operator are co-referential, as illustrated in (84).

$$
\begin{aligned}
& \text { Zhangsan }_{\mathrm{i}} \text { mai yige } \text { baozi }_{\mathrm{j}} \quad \text { pro }_{\mathrm{i}} \text { chi } \Phi_{\mathrm{j}} \\
& \text { Zhangsan buy one-CLASS steamed-stuffed-bun eat } \\
& \text { 'Zhangsan bought a steamed stuffed bun and ate it.' }
\end{aligned}
$$

Zhangsan gei Lisi $_{\mathrm{i}}$ yizhi $\quad$ yan $_{\mathrm{j}} \quad \operatorname{pro}_{\mathrm{i}}$ chou $\Phi_{\mathrm{j}}$

Chinese Zhangsan give Lisi one-CLASS cigarette smoke 'Zhangsan gave Lisi a cigarette and Lisi smoked it.'

Zhangsan $_{\mathrm{i}}$ ba luobo $_{\mathrm{j}}$ pro $_{\mathrm{i}}$ mai $\Phi_{\mathrm{j}}$

Chinese

Zhangsan pull turnip sell

'Zhangsan pulls turnips and sells them.'

Zhangsan $_{\mathrm{i}}$ ba dingzi pro $_{\mathrm{i}}$ yong $\Phi_{\mathrm{j}}$

Chinese

\section{Zhangsan pull nail use}

'Zhangsan pulls the nail and uses it.'

The projection of the null constituent is to satisfy the selection constraint on the head. The transitive verb requires an object. When the transitive verb is followed by no overt NP, it projects a null object. In this way the selection constraint is satisfied. Only the constituent that is selected can project. In other words, the missing constituent in the VP must be the object of the transitive verb (Li 2005). The null numeral must be licensed. If $\mathrm{O} 2$ or the null constituent marked with Case can be a condition on licensing the null numeral, it can be inferred that the grammaticality of the indefinite QP is relevant to the occurrence of O2. In general, SVCs with $\mathrm{O} 2$ as the shared object can license QP.

\section{CONCLUSION}

The present study is mainly concerned with word order and constituency of serial verb constructions. It is argued that structurally the two basic forms of SVCs are $\mathrm{S}+\mathrm{V} 1+\mathrm{O} 1+\mathrm{V} 2+\mathrm{O} 2$ and $\mathrm{S}+\mathrm{O} 1+\mathrm{V} 1+\mathrm{O} 2+\mathrm{V} 2$. Both SVO-type and SOV-type SVCs follow the Temporal Iconicity, which is associated with the asymmetric nature of syntactic structure, i.e. V1 or VP1 c-commands V2 or VP2 asymmetrically. Based on this argument, an analysis for the derivation of SVCs - Inter-VP Asymmetrical C-command Analysis - is proposed and used to account for the derivation of SVCs in various languages. It is argued that in the SVC there exist a null predicate and a null argument, the occurrence or non-occurrence of which gives rise to different types of SVCs. The paper proves that the formal theory can account for the word order-related facts in the SVC, which is associated with the asymmetric nature of syntactic structure. On this basis, the SVC can be regarded as a verb-complement construction, of which V2 is only the complement of V1 or VP1 to represent result, state or goal. On the other hand, V1, which precedes V2 and is above V2 in terms of syntactic structure, is in the position of main predicate, and as a result, V1 or VP1 c-commands V2 or VP2 asymmetrically. This analysis determines the word order of V1 preceding V2 in the SVC and the former being higher than the latter in terms of syntactic hierarchy. SVCs arise from 
the deletion of the conjunction between two clauses and LPD. LPD triggers the movement of VP1's specifier to [Spec IP] and the occurrence of VP2's specifier as pro. Object gapping triggers the ATB movement of VP2 to generate various types of SVCs. It is argued that the differences between coordinative constructions, pivotal constructions and SVCs lie in their internal structure but not in the verb position.

\section{REFERENCES}

Авон Enoch. 2009. “Clause Structure and Verb Series.” Linguistic Inquiry 40(1), 1-33.

Abraham Werner, Epstein Samuel David, Thráinsson Höskuldur, Zwart Jan-Wouter (eds.). 1996. Minimalist Ideas: Syntactic Studies in the Minimalist Framework. Amsterdam-Philadelphia: John Benjamins.

Aikhenvald Alexandra. 2005. "Serial Verb Construction in Typological Perspective." In: Aikhenvald \& Dixon 2005.

Aikhenvald Alexandra, Dixon Robert Malcolm Ward (eds.). 2005. Serial Verb Constructions: A Cross-Linguistic Typology. Oxford: Oxford University Press.

AN Duk-Ho. 2006. "Asymmetric T-to-C Movement in ATB Constructions: A PF Deletion Analysis." Proceedings of ConSOLE XIV, 1-19, http://www.sole.leidenuniv.nl.

Anagnostopoulou Elena. 2003. The Syntax of Ditransitives: Evidence from Clitics. Berlin: Mounton de Gruyter.

Arends Jacques, Muysken Pieter, Smith Norval (eds.) 1995. Pidgins and Creoles: An Introduction. Philadelphia: John Benjamins.

BAKer Mark. 1989. "Object Sharing and Projection in Serial Verb Constructions.” Linguistic Inquiry 20, 513-554.

BAKer Mark. 2002. On Zero Agreement and Polysynthesis. Ms., Rutgers University.

Baker Mark, Stewart Osamuyimen. 2002. A Serial Verb Construction Without Constructions. Ms., Rutgers University.

BARSS Andrew, LASNIK Howard. 1986. "A Note on Anaphora and Double Objects." Linguistic Inquiry 17, 347354.

Beck Sigrid, Johnson Kyle. 2004. "Double Objects Again.” Linguistic Inquiry 35, 97-124.

Beermann Dorothee, Hellan Lars (eds.). 2003. Proceedings of the Workshop on Multi-Verb Constructions Trondheim. Trondheim: Norwegian University of Science and Technology.

Belletti Adriana (ed.). 2004. Structures and Beyond: The Cartography of Syntactic Structures. Oxford: Oxford University Press.

Bierwisch Manfred, HeIdolph Karl Erich (eds.). 1970. Progress in Linguistics. The Hague: Mouton.

BošKović Željko. 1997. "Coordination, Object Shift, and V-movement." Linguistic Inquiry 28, 357-364.

BRUENING Benjamin. 2010. "Double Object Constructions Disguised as Prepositional Datives." Linguistic Inquiry 41, 287-305.

CAMPBell Richard. 1989. The Grammatical Structure of Verbal Predicates. Ph.D. dissertation, UCLA.

CARSTEns Vicki. 2002. "Antisymmetry and Word Order in Serial Constructions." Language 70(1), 3-50.

Chafe Wallace. 1979. "The Flow of Thought and the Flow of Language.” In: Givón 1979: 159-181.

Chang Claire Hsun-huei. 1990. "On Serial Verbs in Mandarin Chinese: VV Compounds and Co-verbial Phrases." Ohio State University Working Papers in Linguistics 39, 288-315.

Cheng Gong. 1999. Linguistic Universalism. Shanghai: Shanghai Foreign Language Education Press.

Choi Seongsook. 2003. "Serial Verbs and the Empty Category." In: Beermann \& Hellan 2003: 39-48.

Chomsky Noam. 1995. The Minimalist Program. Cambridge, MA: MIT Press.

Сномsкy Noam. 1999. "Derivation by Phase." MIT Occasional Papers in Linguistics 18. [Revised version appeared as CHOMSKY 2001].

Chomsky Noam. 2000. "Minimalist Inquiries: the Framework.” In: Martin et al. 2000: 89-155.

Chomsky Noam. 2001. "Derivation by Phase." In: Kenstowicz 2001: 1-52.

Сномsкy Noam. 2004. "Beyond Explanatory Adequacy.” In: Belletti 2004: 104-131.

Сномкку Noam. 2005. “Three Factors in Language Design.” Linguistic Inquiry 36, 1-22.

ChOmsky Noam. 2007. “Approaching UG from Below.” In: SAUERLAND \& GärTNER 2007: 1-29.

Collins Chris. 1997. "Argument Sharing in Serial Verb Constructions." Linguistic Inquiry 28(3), 461-497.

ComRIE Bernard. 1985. Tense. Cambridge: Cambridge University Press. 
DAI John Xiang-ling. 1990. "Syntactic Constructions in Serial Verb Expressions in Chinese." In: JosEPH \& ZWICKY 1990: 316-339.

DAI Manchun. 2003. "Generalized Derivations in Syntactic Computations.” Foreign Language Teaching and Research 3, 170-178.

DAI Qingxia, QIU Yue. 2008. “On the Typological Characteristics of the Serial Verb Constructions in OV Type Tibeto-Burman Languages." Chinese Teaching in the World 2, 72-82.

Dechaine Rose-Marie. 1988. "Towards a Typology of Serial Constructions in Haitian." Niger Congo Syntax and Semantics 1, 49-64.

Den Dikken Marcel, Sybesma Rint. 1998. Take Serials Light up the Middle. Paper Presented at the 20th GLOW Colloquim, Tilburg.

de Vega Manuel, Robertson David, Glenberg Arthur, Kaschak Michael, Rinck Mike. 2004. “On Doing Two Things at Once: Temporal Constraints on Actions in Language Comprehension.” Memory \& Cognition 32(7), 1033-1043.

Dixon Robert Malcolm Ward. 1997. The Rise and Fall of Languages. Cambridge: Cambridge University Press.

DowTy David. 1986. "The Effects of Aspectual Class on the Temporal Structure of Discourse: Semantics or Pragmatics?" Linguistics \& Philosophy 9, 37-61.

Emonds Joseph Embley, Ostler Rosemarie Whitney. 2005. “Double Object Constructions.” In: EvERAERT \& vaN RIEMSDIJK 2005: 73-144.

Everaert Martin, van Riemsdiuk Henk (eds.). 2005. The Blackwell Companion to Syntax. Oxford: Blackwell.

Ferguson Scott. 1996. "Shortest Move and Object Case Checking." In: Abraham et al. 1996: 97-111.

Gazdar Gerald, Pullum Geoffrey, SAG Ivan, WASOw Thomas. 1982. "Coordination and Transformational Grammar." Linguistic Inquiry 13, 663-677.

Givón Talmy (ed.). 1979. Syntax and Semantics. Vol. 12. Discourse and Syntax. New York: Academic Press.

Givón Talmy. 1992. "The Grammar of Referential Coherence as Mental Processing Instructions.” Linguistics $30,5-55$.

Goodall Grant. 1987. Parallel Structures in Syntax. Cambridge: Cambridge University Press.

Haegeman Liliane (ed.). 1997. Elements of Grammar: Handbook of Generative Syntax. Dordrecht: Kluwer.

Hale Ken. 1991. "Misumalpan Verb Sequencing Constructions.” In: Lefebvre (ed.) 1991: 1-35.

Hankamer Jorge, Sag Ivan. 1976. “Deep and Surface Anaphora.” Linguistic Inquiry 7, 391-428.

He Xiaowei. 2009. "Some Reflections on Generative Studies of the Double Object Construction." Contemporary Linguistics 3, 216-223.

Hopper Paul. 1979. “Aspect and Foregrounding in Discourse.” In: Givón 1979: 213-241.

Hornstein Norbert, Nunes Jairo, Grohmann Kleanthes. 2005. Understanding Minimalism. Cambridge: Cambridge University Press.

JaCKendoff Ray. 1977. X-Bar Syntax: A Study of Phrase Structure. Cambridge, MA: MIT Press.

JACKENDOFF Ray. 1990. Semantic Structures. Cambridge, MA: MIT Press.

JANSEn Bert, Koopman Hilda, Muysken Pieter. 1978. "Serial Verbs in the Creole Languages." Amsterdam Creole Studies 2, 125-159.

Joseph Brian, Zwicky Arnold (eds.). 1990. When Verbs Collide: Papers from the Ohio State Mini-Conference on Serial Verbs. Ohio State University.

KARI Ethelbert. 2003. "Serial Verb Constructions in Degema, Nigeria." African Study Monographs 24(4), 271289.

KaYNE Richard. 1994. The Antisymmetry of Syntax. Cambridge, MA: MIT Press.

Kenstowicz Michael (ed.). 2001. Ken Hale: A Life in Language. Cambridge, MA: MIT Press.

Koopman Hilda. 1984. The Syntax of Verbs: From Verb Movement in the Kru Languages to Universal Grammar. Dordrecht: Foris.

Koopman Hilda, Sportiche Dominique. 1991. "The Position of Subjects.” Lingua 85, 211-258.

Kratzer Angelika. 1996. "Severing the External Argument from Its Verb.” In: Rooryck \& ZARING 1996: 109137.

Kuroda Sige-Yuki. 1988. "Whether We Agree or Not: the Comparative Syntax of English and Japanese.” In: POSER 1988: 315-357.

Lappin Shalom, Benmamoun Elabbas (eds.). 1999. Fragments: Studies in Ellipsis and Gapping. Oxford: Oxford University Press.

LARSON Richard. 1988. “On the Double Object Construction.” Linguistic Inquiry 19, 335-392.

LARSON Richard. 1990. "Double Object Revisited: A Reply to Jackendoff.” Linguistic Inquiry 21, 589-632. 
Lefebvre Claire. 1991. “Take Serial Verb Constructions in Fon.” In: Lefebvre (ed.) 1991: 103-136.

Lefebvre Claire (ed.). 1991. Serial Verbs: Grammatical, Comparative and Cognitive Approaches. Amsterdam: John Benjamins.

Li Charles, Thompson Sandra. 1981. Mandarin Chinese: A Functional Reference Grammar. Berkeley: University of California Press.

Li Yafei. 1990. "On V-V Compounds in Chinese.” Natural Language and Linguistic Theory 8, 177-207.

Li Yafei. 1991. “On Deriving Serial Verb Constructions.” In: Lefebvre (ed.) 1991: 103-136.

Li Yafei. 2007. "On Temporal Iconicity in the Serial Verb Construction." Linguistic Sciences 6, 3-10.

Li Yen-hui Audrey. 1985. Abstract Case in Chinese. Ph.D. dissertation, University of Southern California, Los Angeles, CA.

Li Yen-hui Audrey. 2005. "Ellipsis and Missing Objects.” Linguistic Sciences 2, 3-10.

LiU Gang. 1997. Eine unifikations-basierte Grammatik für das moderne Chinesisch-dargestellt in der HPSG. Ph.D. dissertation, Universität Konstanz, Germany.

LoBeck Anne. 1995. Ellipsis: Functional Heads, Licensing and Identification. Oxford: Oxford University Press.

LoBECK Anne. 1999. "VP Ellipsis and the Minimalist Program: Some Speculations and Proposals." In: LAPPIN \& Benmamoun 1999: 98-123.

Lord Carol. 1974. "Causative Constructions in Yoruba." Studies in African Linguistics 5, 195-204.

Manfredi Victor (ed.). 1988. Niger-Congo Syntax and Semantics 1. Boston: Boston University African Studies Center.

Martin Roger, Michaels David, Uriagereka Juan (eds.). 2000. Step by Step: Essays on Minimalism in Honor of Howard Lasnik. Cambridge, MA: MIT Press.

Matthews Peter Hugoe. 2000. Concise Dictionary of Linguistics. Shanghai: Shanghai Foreign Language Education Press.

McCloskey Jim. 1997. "Subjecthood and Subject Positions." In: Haegeman 1997: 197-232.

Müller Stefan (ed.). 2009. Proceedings of the 16th International Conference on Head-Driven Phrase Structure Grammar. Stanford: CSLI Publications.

MüLLER Stefan, LiPenkova Janna. 2009. “Serial Verb Constructions in Chinese: An HPSG Account.” In: MüLleR 2009: 234-254.

Munn Alan. 1993. Topics in the Syntax and Semantics of Coordinate Structures. Ph.D. dissertation. University of Maryland at College Park.

MuYsKen Pieter. 1988. "Parameters for Serial Verbs." In: MANFredi 1988: 65-75.

Muysken Pieter, Veenstra Tonjes. 1995. "Serial Verbs." In: Arends et al. 1995: 289-301.

Nunes Jairo. 1995. The Copy Theory of Movement and the Linearization of Chains in the Minimalist Program. Ph.D. dissertation, University of Maryland, College Park.

PAul Waltraud. 2005. "The 'Serial Verb Construction' in Chinese: A Gordian Knot." The Linguistic Review 25, $367-411$.

POSER William (ed.). 1988. Papers from the Second International Workshop on Japanese Syntax. Stanford: CSLI Publications.

Rooryck Johan, Zaring Laurie (eds.). 1996. Phrase Structure and the Lexicon. Dordrecht: Kluwer.

Ross John Robert. 1967. Constraints on Variables in Syntax. Ph.D. dissertation, MIT.

Ross John Robert. 1970. "Gapping and the Order of Constituents." In: Bierwisch \& Heidolph 1970: 249-259.

SaG Ivan, Gerald Gazdar, Wasow Thomas, Weisler Steven. 1985. "Coordination and How to Distinguish Categories." Natural Language and Linguistic Theory 3, 117-171.

SAITo Mamoru. 1985. Some Asymmetries in Japanese and Their Theoretical Implications. PhD dissertation, MIT.

SAUERLAND Uli, GärTner Hans Martin (eds.). 2007. Interfaces + Recursion = Language?. Berlin-New York: Mounton de Gruyter.

SCHACHTER Paul. 1974. "A Non-transformational Account of Serial Verbs." Studies in African Linguistics Supplement $5,153-271$.

SChiller Eric. 1991. An Autolexical Account of Subordinating Serial Verb Constructions. Ph.D. dissertation, University of Chicago.

Sebba Mark. 1987. The Syntax of Serial Verbs: An Investigation into Serialisation in Sranan and Other Languages. Amsterdam: John Benjamins.

Sportiche Dominique. 1988. "A Theory of Floating Quantifiers and Its Corollaries for Constituent Structure.” Linguistic Inquiry 19, 425-449.

STAhlKe Herbert. 1970. "Serial Verbs.” Studies in African Linguistics 1, 60-99. 
TAI James Hao-yi. 2002. "Conceptual Structures and Non-autonomous Syntax: Some Conceptualization Principles in Chinese Grammar." Contemporary Linguistics 1, 1-12.

TAO Liang. 2009. "Serial Verb Construction in Mandarin Chinese: The Interface of Syntax and Semantics." In: Yun 2009: 209-228.

TSAI Wei-Tien Dylan. 1994. "On Nominal Islands and LF Extractions in Chinese." Natural Language and Linguistic Theory 12, 121-175.

Travis Lisa. 1984. Parameters and Effects of Word Order Variation. Ph.D. dissertation, MIT.

van Hout Angeliek. 1998. Event Semantics of Verb Frame Alternations: A Case Study of Dutch and Its Acquisition. New York: Garland Publishing.

WANG Xin. 2007. "Notes about Serial Verb Construction in Chinese." California Linguistic Notes 1, 1-15.

Williams Edwin. 1978. "Across-the-board Rule Application.” Linguistic Inquiry 9, 31-43.

Williamson Kay. 1965. A Grammar of the Kolokuma Dialect of Ijo. Cambridge: Cambridge University Press.

XIAO Yun (ed.). 2009. Proceedings of the 21st North American Conference on Chinese Linguistics (NACCL-21). Vol. 2. Smithfield, Rhode Island: Bryant University.

YANG Yongzhong. 2007a. "On the Pragmatic Motivation of Vi+NP." Chinese Linguistics 1, 58-65.

YANG Yongzhong. 2007b. "The Syntactic Status of NP in Vi+NP." Studies in Language and Linguistics 2, 59-64.

YANG Yongzhong. 2009. "A Reanalysis of Temporal Iconicity in the Serial Verb Construction." Tianjin Foreign Studies University Journal 5, 11-18.

YANG Yongzhong. 2011. "Non-prototypical Patient Object Sentences in Chinese." Philippine Journal of Linguistics 42, 105-127. 